NASA/TM-2011-216982

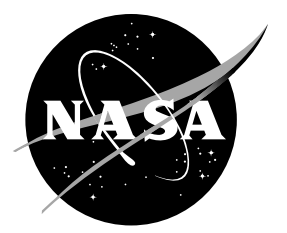

\title{
Terahertz Computed Tomography of NASA Thermal Protection System Materials
}

D.J. Roth

Glenn Research Center, Cleveland, Ohio

S. Reyes-Rodriguez

Michigan State University, East Lansing, Michigan

D.A. Zimdars

Picometrix, LLC, Ann Arbor, Michigan

R.W. Rauser

University of Toledo, Toledo, Ohio

W.W. Ussery

Lockheed Martin Space Systems Company, Denver, Colorado 


\section{NASA STI Program . . . in Profile}

Since its founding, NASA has been dedicated to the advancement of aeronautics and space science. The NASA Scientific and Technical Information (STI) program plays a key part in helping NASA maintain this important role.

The NASA STI Program operates under the auspices of the Agency Chief Information Officer. It collects, organizes, provides for archiving, and disseminates NASA's STI. The NASA STI program provides access to the NASA Aeronautics and Space Database and its public interface, the NASA Technical Reports Server, thus providing one of the largest collections of aeronautical and space science STI in the world. Results are published in both non-NASA channels and by NASA in the NASA STI Report Series, which includes the following report types:

- TECHNICAL PUBLICATION. Reports of completed research or a major significant phase of research that present the results of NASA programs and include extensive data or theoretical analysis. Includes compilations of significant scientific and technical data and information deemed to be of continuing reference value. NASA counterpart of peer-reviewed formal professional papers but has less stringent limitations on manuscript length and extent of graphic presentations.

- TECHNICAL MEMORANDUM. Scientific and technical findings that are preliminary or of specialized interest, e.g., quick release reports, working papers, and bibliographies that contain minimal annotation. Does not contain extensive analysis.

- CONTRACTOR REPORT. Scientific and technical findings by NASA-sponsored contractors and grantees.
- CONFERENCE PUBLICATION. Collected papers from scientific and technical conferences, symposia, seminars, or other meetings sponsored or cosponsored by NASA.

- SPECIAL PUBLICATION. Scientific, technical, or historical information from NASA programs, projects, and missions, often concerned with subjects having substantial public interest.

- TECHNICAL TRANSLATION. Englishlanguage translations of foreign scientific and technical material pertinent to NASA's mission.

Specialized services also include creating custom thesauri, building customized databases, organizing and publishing research results.

For more information about the NASA STI program, see the following:

- Access the NASA STI program home page at http://www.sti.nasa.gov

- E-mail your question via the Internet to help@ sti.nasa.gov

- Fax your question to the NASA STI Help Desk at $443-757-5803$

- Telephone the NASA STI Help Desk at 443-757-5802

- Write to: NASA Center for AeroSpace Information (CASI) 7115 Standard Drive Hanover, MD 21076-1320 
NASA/TM-2011-216982

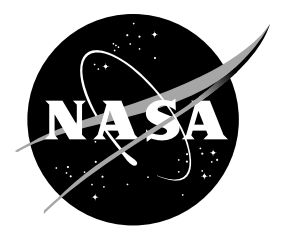

\section{Terahertz Computed Tomography of NASA Thermal Protection System Materials}

D.J. Roth

Glenn Research Center, Cleveland, Ohio

S. Reyes-Rodriguez

Michigan State University, East Lansing, Michigan

D.A. Zimdars

Picometrix, LLC, Ann Arbor, Michigan

R.W. Rauser

University of Toledo, Toledo, Ohio

W.W. Ussery

Lockheed Martin Space Systems Company, Denver, Colorado

Prepared for the

38th Annual Review of Progress in Quantitative Nondestructive Evaluation (QNDE) sponsored by QNDE Programs

Burlington, Vermont, July 17-22, 2011

National Aeronautics and

Space Administration

Glenn Research Center

Cleveland, Ohio 44135 
This report is a preprint of a paper intended for presentation at a conference.

Because changes may be made before formal publication, this preprint is made available with the understanding that it will not be cited or reproduced without the permission of the author.

Trade names and trademarks are used in this report for identification only. Their usage does not constitute an official endorsement, either expressed or implied, by the National Aeronautics and Space Administration.

Level of Review: This material has been technically reviewed by technical management.

Available from

NASA Center for Aerospace Information 7115 Standard Drive

Hanover, MD 21076-1320
National Technical Information Service 5301 Shawnee Road Alexandria, VA 22312

Available electronically at http://www.sti.nasa.gov 


\title{
Terahertz Computed Tomography of NASA Thermal Protection System Materials
}

\author{
D.J. Roth \\ National Aeronautics and Space Administration \\ Glenn Research Center \\ Cleveland, Ohio 44135 \\ S. Reyes-Rodriguez \\ Michigan State University \\ East Lansing, Michigan 48824 \\ D.A. Zimdars \\ Picometrix, LLC \\ Ann Arbor, Michigan 48104 \\ R.W. Rauser \\ University of Toledo \\ Toledo, Ohio 43606 \\ W.W. Ussery \\ Lockheed Martin Space Systems Company \\ Denver, Colorado 80201
}

\begin{abstract}
A terahertz axial computed tomography system has been developed that uses time domain measurements in order to form cross-sectional image slices and three-dimensional volume renderings of terahertz-transparent materials. The system can inspect samples as large as $0.0283 \mathrm{~m}^{3}\left(1 \mathrm{ft}^{3}\right)$ with no safety concerns as for x-ray computed tomography. In this study, the system is evaluated for its ability to detect and characterize flat bottom holes, drilled holes, and embedded voids in foam materials utilized as thermal protection on the external fuel tanks for the Space Shuttle. X-ray micro-computed tomography was also performed on the samples to compare against the terahertz computed tomography results and better define embedded voids. Limits of detectability based on depth and size for the samples used in this study are loosely defined. Image sharpness and morphology characterization ability for terahertz computed tomography are qualitatively described.
\end{abstract}

\section{Introduction}

Terahertz energy refers to electromagnetic waves propagating at frequencies between the highfrequency edge of the microwave band $(300 \mathrm{GHz})$ and the low frequency edge of far-infrared light (3 THz) (Ref. 1). Within the last 15 years, the terahertz (THz) spectral range has experienced a revolution in instrumentation and applications due to the synthesis of two emerging fields, ultrafast laser development and optoelectronics (Refs. 2 to 8). The time domain THz pulse-echo nondestructive evaluation (NDE) method has proven very useful in the inspection of external tank foam, shuttle underbelly tiles, ceramic materials, layered and coated materials, and certain composite materials (Ref. 5). In these studies, the $\mathrm{THz}$ energy penetrates a THz-transparent material (generally a dielectric material) and is reflected from a substrate of differing index of refraction, thus providing information on the internal quality state of the dielectric. Electrically-conducting materials strongly reflect $\mathrm{THz}$ energy and are ideal as reflective substrates and cannot be penetrated by $\mathrm{THz}$ energy. THz computed tomography 
(CT) has also been developed to allow cross-sectional characterization of dielectric materials (without a reflecting substrate) (Refs. 9 and 10).

The THz-CT system developed utilizes time-domain (TD) time-of-flight measurements to form sinograms, cross-sectional slices, and three-dimensional volume renderings of dielectric materials. The time-of-flight of terahertz energy is proportional to the cumulative sum of the amount of material times the average index of refraction for that material and thus is considered an ideal parameter to measure material change. CT TD-THz can precisely locate features within a three-dimensional volume, such as voids and disbonds, and provide a three-dimensional representation of the material within the limits of its resolution.

CT-TD-THz is a more challenging problem than x-ray, MRI, or positron tomography because the $\mathrm{THz}$ wavelength is much larger, requiring careful focusing and collimation of the TD-THz beam. X-ray $\mathrm{CT}$ would also hold the advantage over THz-CT with regards to it being applicable to a much broader range of materials since x-ray can penetrate metallic materials. However, TD-THz is substantially shorter wavelength than microwaves or millimeter waves, and the beams can propagate with near-geometrical optics. In certain CT inspection situations where lower resolutions are acceptable, and where the safety concerns of x-ray ionizing radiation cannot be accommodated, THz-CT may be able to play an inspection role and thus requires evaluation. Of particular interest to NASA is the application of this technology to thermal protection system materials. It has been determined that terahertz pulses can penetrate as much of $20 \mathrm{~cm}$ of foam with a maximum frequency of up to $300 \mathrm{GHz}(>1 \mathrm{THz}$ for thinner foam) and are scattered by voids allowing void detection (Ref. 5).

In this study, the THz-CT system is evaluated for its ability to detect and characterize flat bottom holes, drilled holes, and embedded voids in foam materials utilized as thermal protection on the external fuel tanks for the Space Shuttle. Micro-focus X-ray CT is utilized to characterize voids and provide a baseline for comparison to the $\mathrm{THz} \mathrm{CT}$. Other applications of the terahertz CT method that may be of interest to NASA include inspection of Kevlar-based composites, and Kevlar and Zylon fabric covers for fan containment. The ability of TD-THz to generate three-dimensional representations of the interior of objects has the potential to be of great utility to aerospace NDE in general.

\section{Terahertz CT System Description}

Axial transmission tomographic-type three-dimensional imaging requires that the object be scanned in transmission mode and from all angles, requiring access to both sides of the sample. Figure 1 shows the concept (Fig. 1(a)) and terahertz CT system (Fig. 1(b)) which uses a transmitter-receiver arrangement with collimating confocal imaging lenses to achieve an approximately $2 \mathrm{~mm}$ spot size. The equations for the beam diameter and Rayleigh range (which is the distance over which the wave phase front is approximately planar) for confocal transmission CT-TD-THZ are:

$$
\begin{gathered}
Z_{R} \equiv \frac{\pi w_{0}^{2}}{\lambda} \\
w_{0} \approx \frac{\lambda}{\pi \theta_{\text {module }} m}
\end{gathered}
$$

where $Z_{R}$ is the Rayleigh range, $w_{0}$ is the beam radius at the waist, $\lambda$ is the wavelength of the terahertz energy, $\theta_{\text {module }}$ is the divergence angle from the THz module ( $\sim 0.2$ for Picometrix' THz modules), and $m$ is the magnification of the $\mathrm{THz}$ focusing lens (Ref. 11). Figure 2 shows a sketch describing the parameters. 


\section{TD-THz Computed Axial Tomography System Concept}

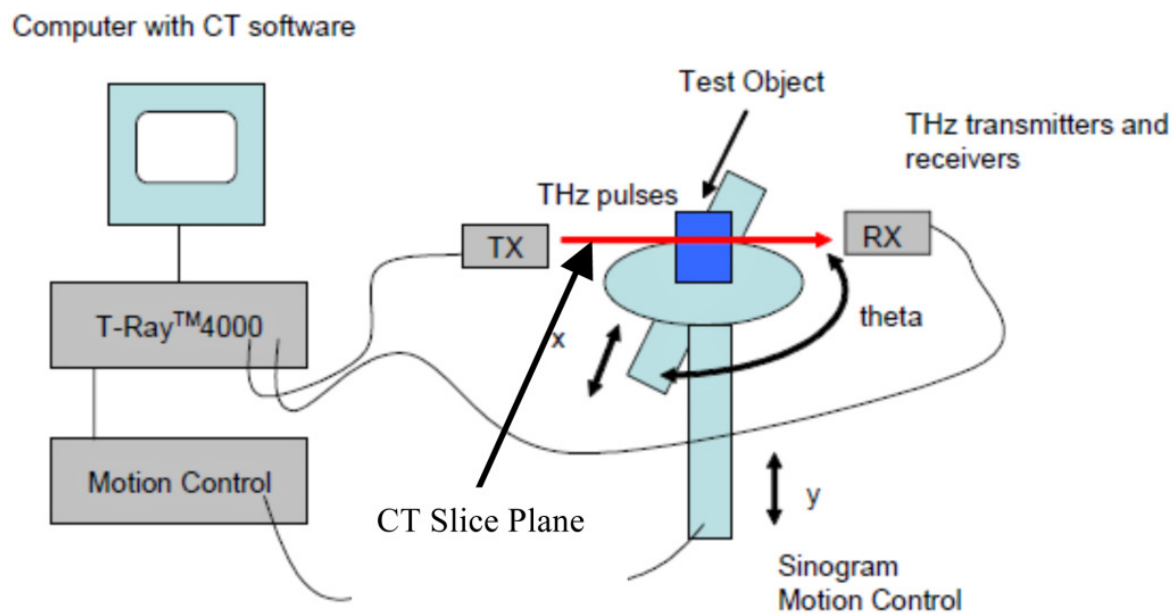

(a) THz-CT system concept

Motion Control

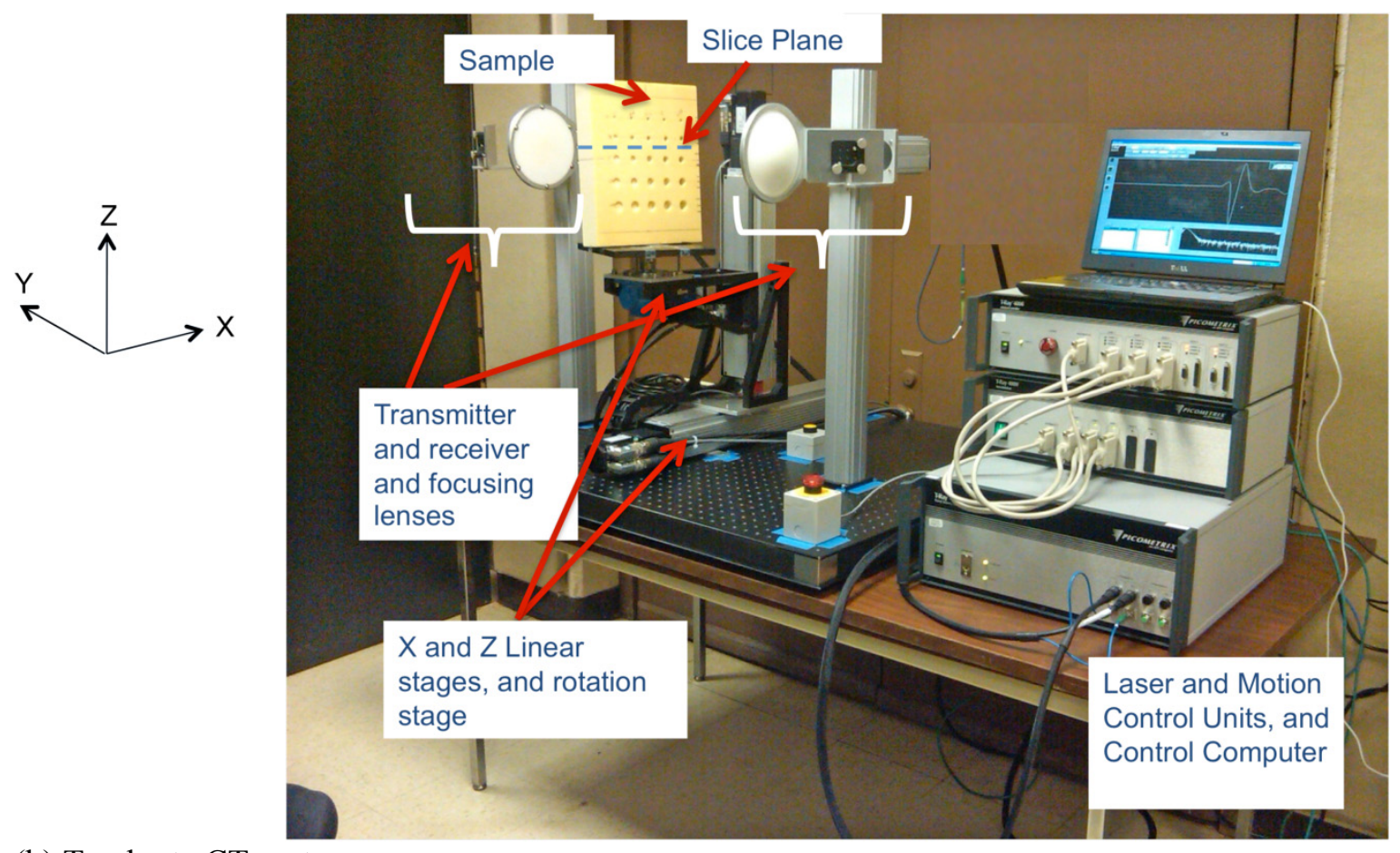

(b) Terahertz CT system

Figure 1.-THz-CT system concept and terahertz CT system. 


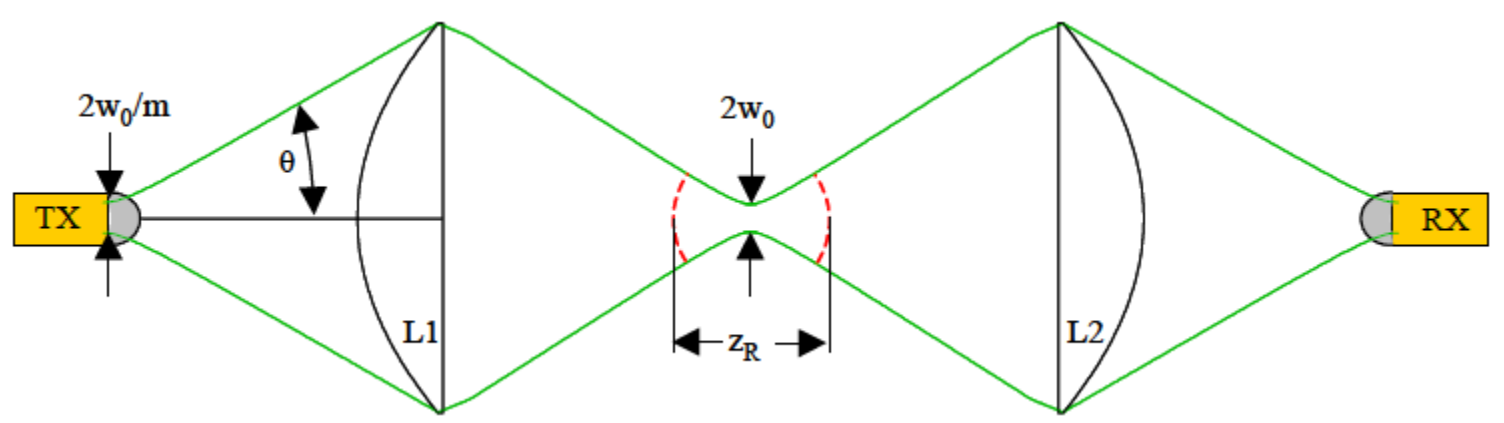

Figure 2.-Sketch of confocal transmission CT-TD-THz transmit-receive arrangement with lenses.

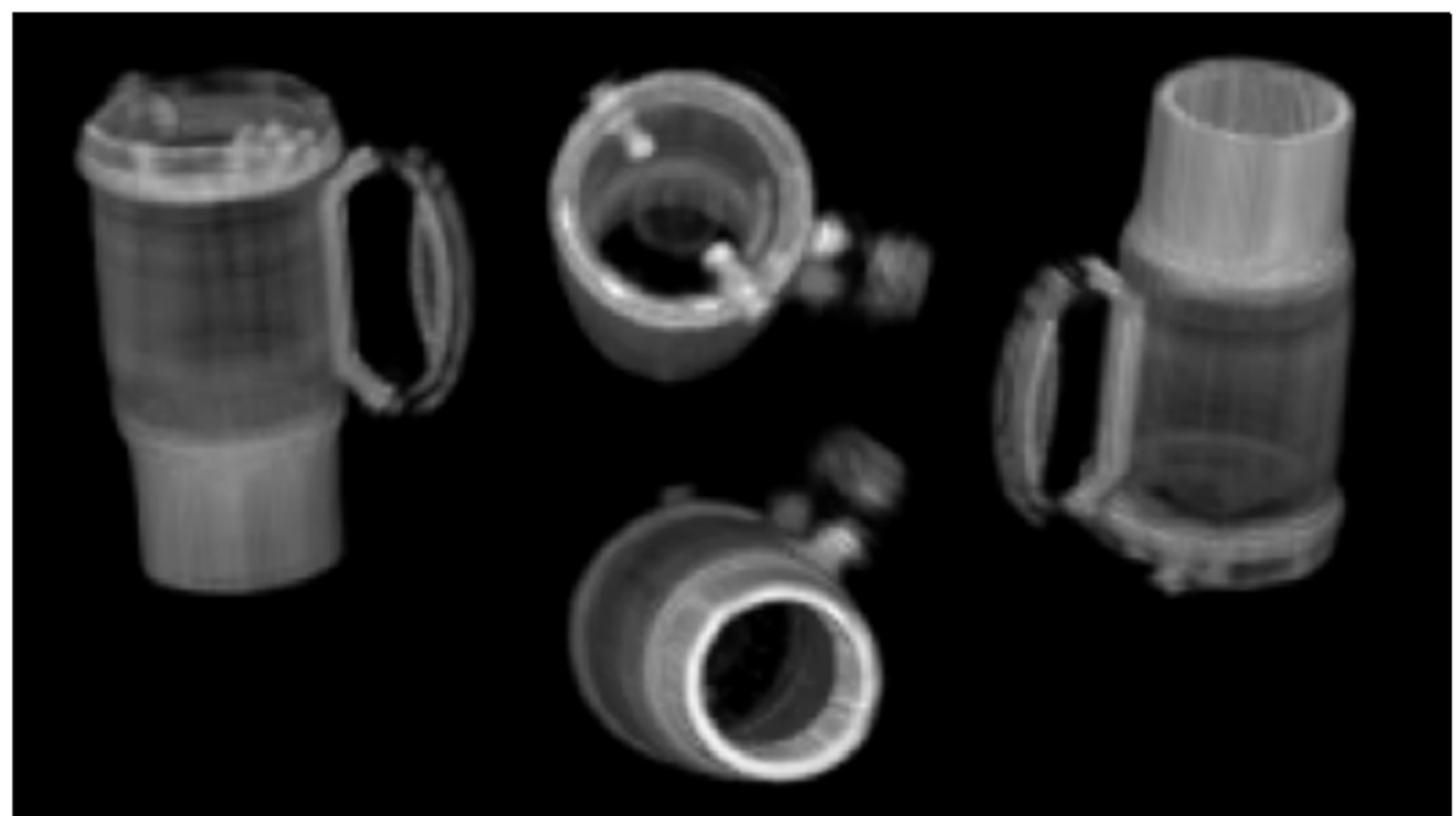

Figure 3.-Several semi-transparent views of a THz CT volume rendering of a plastic molded coffee cup with lid. Cup is about $10 \mathrm{~cm}$ in diameter at its largest point.

In previous $\mathrm{CT} \mathrm{THz}$ work, Reference 10 claim that the Rayleigh range of the $\mathrm{THz}$ beam should be larger than the size of the target. The lenses employed in this system were F/ $2 \mathrm{f}$-number and $7 \mathrm{in}$. focal length lenses giving 0.92 times magnification and resulting in an expected Rayleigh range of 5.4 times the beam diameter or only about $10 \mathrm{~mm}$. The theoretical consequence of this is that there is a tradeoff in CT TD-THz between object size and feature resolution unless improved algorithms can be developed. In practice, the requirement that the Rayleigh range should be larger than the size of the target can be eased allowing object dimensions to exceed the Rayleigh range 5 to 10 times or more, and still obtain acceptable images (see Fig. 3 for several views of a THz CT volume rendering of a plastic molded coffee cup with lid). Resolution in the reconstructed image is estimated to be 1 to $2 \mathrm{~mm}$ in the center of the image with expected graceful degradation of resolution occurring radially from the focus. This degradation could be especially noticeable on larger samples. 
The CT TD-THz system consists of three main sections 1) The kilohertz waveform rate Picometrix T-Ray ${ }^{\circledR} 4000$ control unit, TD-THz transmitter, receiver, umbilicals, lenses, and T-Ray 4000 motion controller; 2) customized motion controllers consisting of a angular/rotational theta axis and $\mathrm{X}$ and $\mathrm{Z}$ axes; and 3) data acquisition software and CT reconstruction software. The T-Ray $4000 \mathrm{THz}$ system employs femtosecond laser methods in a permanently-aligned miniature fiber optic-coupled configuration for generating and detecting near single cycle impulses of radiation spanning frequencies from $40 \mathrm{GHz}$ to $3 \mathrm{THz}$ (hyper-wideband) (Ref. 5). THz energy of these frequencies easily propagates through meters of dry air without significant dispersion/distortions (Ref. 1). The pulsed laser-based technique uses photoconductive antennas to allow terahertz radiation to both be generated and detected at high signal-tonoise (SNR) ratio. Fiber coupling is used from $\mathrm{THz}$ emitter and detector to the control unit which contains the laser, optical delay system, and electronics. The THz CT system utilizes a single transmitter and a single receiver located on opposite sides of the sample. The system is fully automated for data collection. The system has been designed in order to allow samples of up to approximately $0.0283 \mathrm{~m}^{3}$ $\left(1 \mathrm{ft}^{3}\right)$ to be inspected. The sample is rotated and raised in the work envelope, while the THz sensors remain stationary.

The TD-THz pulse generated is a single cycle, polarized, low power pulse. The system collects waveforms over an $80 \mathrm{ps}$ window at $1000 \mathrm{~Hz}$. The waveforms each consist of 400 amplitude samples acquired at 200 femtosecond increments. The SNR for a single waveform without averaging is $35 \mathrm{~dB}$. Usually a high-pass filtering procedure is performed in hardware to remove anomalous low frequency components. Waveform deconvolution with the reference waveform obtained with just air between the transmitter and receiver was performed to deblur waveforms and final image results. A typical received waveform thru a section of foam is shown in Figure 4(a). Center frequency is located at about 0.1 to $0.2 \mathrm{THz}$.

TD-THz axial CT requires the acquisition of a TD-THz waveform at each angular scan increment. Generally, a number of waveforms are acquired at each scan increment and averaged which improves the SNR. The number of waveforms averaged is determined from:

$$
\text { Number of waveforms averaged }=\left(\text { time }[\mathrm{sec}] \text { per } 360^{\circ} \text { revolution }\right) * 1000 / 360^{\circ}
$$

The longer the time for a $360^{\circ}$ revolution, the greater the number of waveforms averaged.

Consider the first $\mathrm{Z}$ position where data will be acquired. One full rotation of $360^{\circ}$ results in one data chord (horizontal line) of a sinogram (Fig. 4(b)). At each angular position of the data chord, the difference between the time-of-flight of the pulse in air and the time of flight of the pulse in the material is calculated. A gray scale value is assigned to the time difference value calculated, with the minimum and maximum time differences being the darkest and lightest values, respectively, in the image. The time-offlight of the pulse in the material gives the optical path length (OPL), which is the sum of the products of the material thicknesses and their refractive indices. After one full rotation, the $\mathrm{X}$ stage is incremented to the next $\mathrm{X}$ position, and another full rotation ensues to obtain another data chord. A complete sinogram (see Fig. 4(b)) with, for example, 150 data chords taken in the horizontal (X) axis takes several minutes. (Data acquisition time for a single slice is roughly equivalent to that required for a conventional twodimensional raster scan.) Multiple sinograms are acquired by stepping the object on the vertical (Z) axis. Obtaining from a time standpoint a practical set of sinograms might consist of acquiring 20 to 30 sinograms.

Two-dimensional cross sectional slice images are then reconstructed from the sinograms using filtered back projection and an inverse Radon transform algorithm with Weiner filtering (Ref. 12). The reconstructions work well if the slice is "binary", that is air/vacuum (index of refraction $[\mathrm{n}]=1$ ) plus some other volumes of homogeneous material $(n>1)$. Foams have $n \sim 1$, so Snell's law and refraction can be ignored. If the structure being investigated consisted of a thin high $\mathrm{n}$ material, refraction should be minimal. Even for thicker higher index of refraction materials $(n \geq 1.5)$ where refraction might be an issue, preliminary investigations have shown the reconstructions to look qualitatively reasonable. 


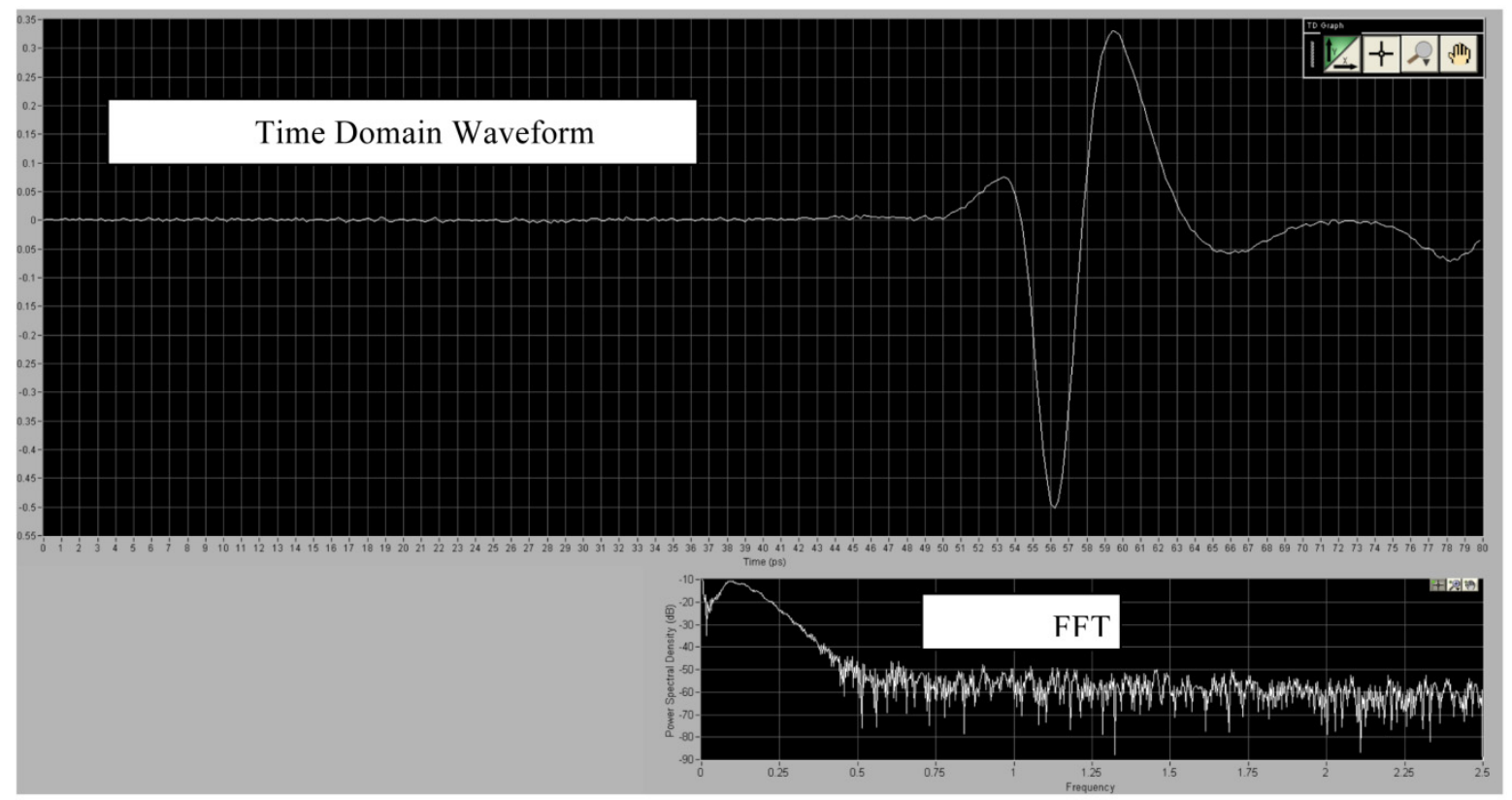

(a) Typical received waveform through foam and Fast Fourier Transform (FFT)

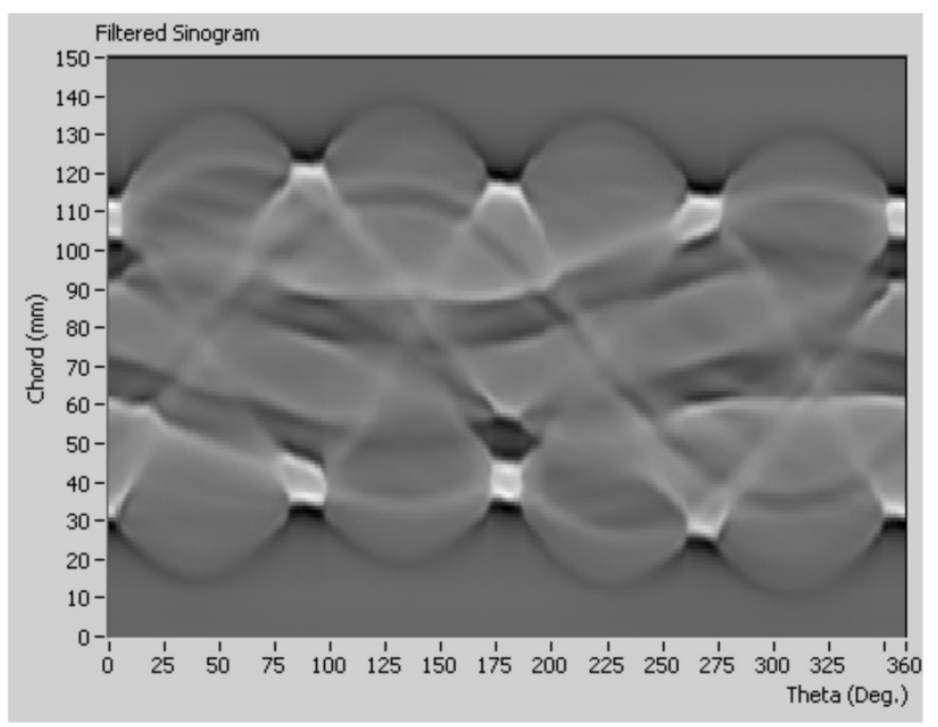

(b) Sinogram of data

Figure 4.-Typical raw data including a received waveform and a complete sinogram consisting of 150 data chords (X positions). 


\section{Space Shuttle External Tank Sprayed on Foam Insulation (SOFI) Samples}

Several samples of sprayed on foam insulation (SOFI) were fabricated. One $300 \mathrm{~mm}(\mathrm{H})$ by $245 \mathrm{~mm}$ (L) by $50.8 \mathrm{~mm}(2 \mathrm{in}$.) (T) sample was fabricated with flat-bottom holes of various diameters (6.35 to $19.05 \mathrm{~mm}$ ) and depths (3.175 to $16.51 \mathrm{~mm})$ (Fig. 5(a)). This sample was originally used as a resolution standard for two-dimensional reflection mode terahertz inspections. The holes in each row have a constant diameter and the holes in each column have a constant depth. For the THz CT inspection of this piece, a second piece of identically-sized foam without holes was pressed against the first piece with the holes so that the holes were covered (Fig. 5(b)). The total thickness then became $101.6 \mathrm{~mm}$ (4 in.) and the hole depths were then $\sim 3,6,9,12$, and 15 percent of thickness (with respect to the $[Y]$ direction of the $\mathrm{THz}$ beam with the sample mounted as shown in Figure 1(b)). CT scans were done one row of holes at a time and the results from several rows are presented. With large samples such as this, it is expected that the resolution would degrade noticeably towards the outer edges due to the small size of the Rayleigh range. An additional sample was also prepared with smaller diameter holes drilled through the sample (Fig. 5(c)) to further address detectability.

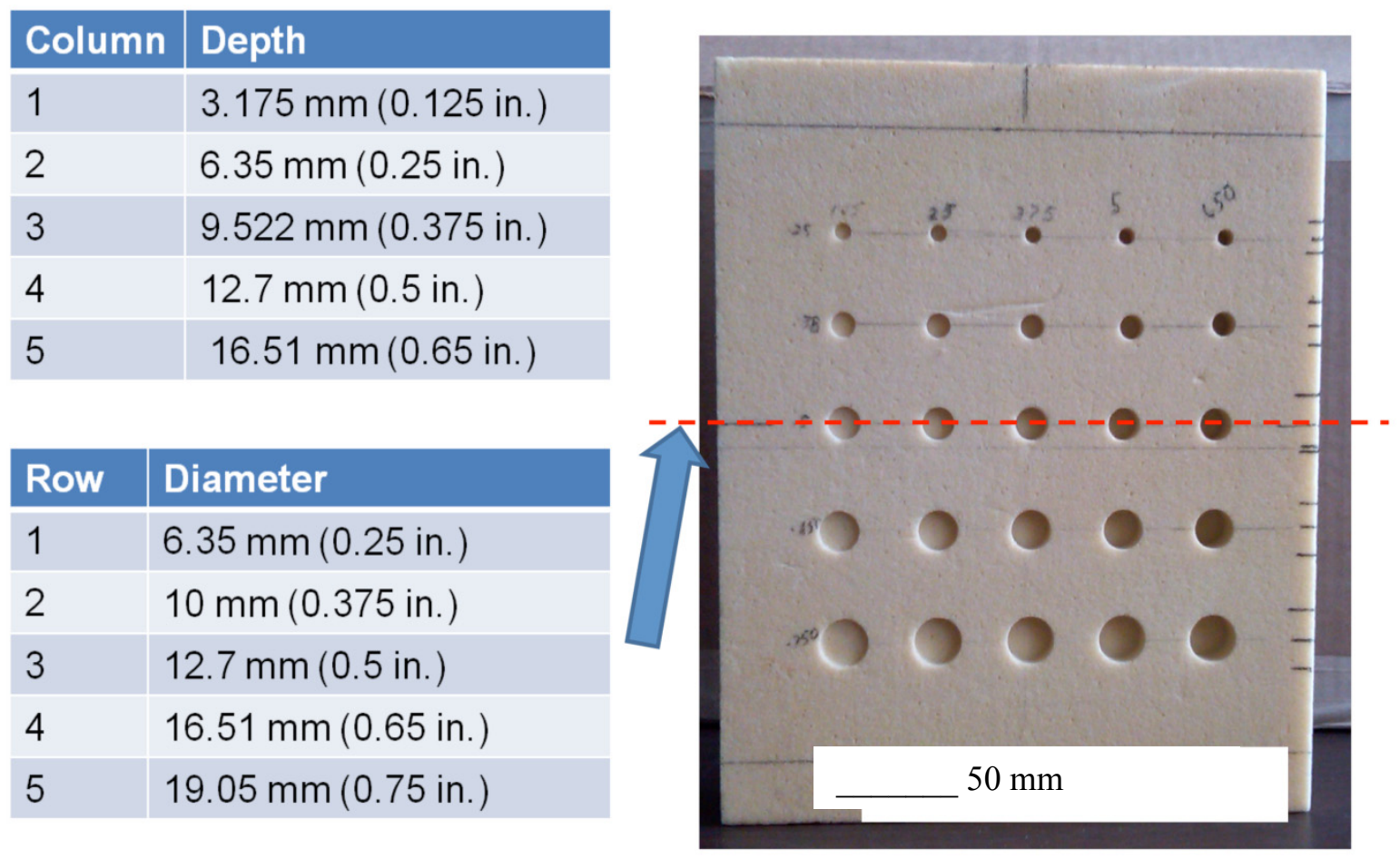

(a) Flat bottom hole sample

Figure 5.-Diameter and depth of holes in flat-bottom hole and drilled hole samples. 


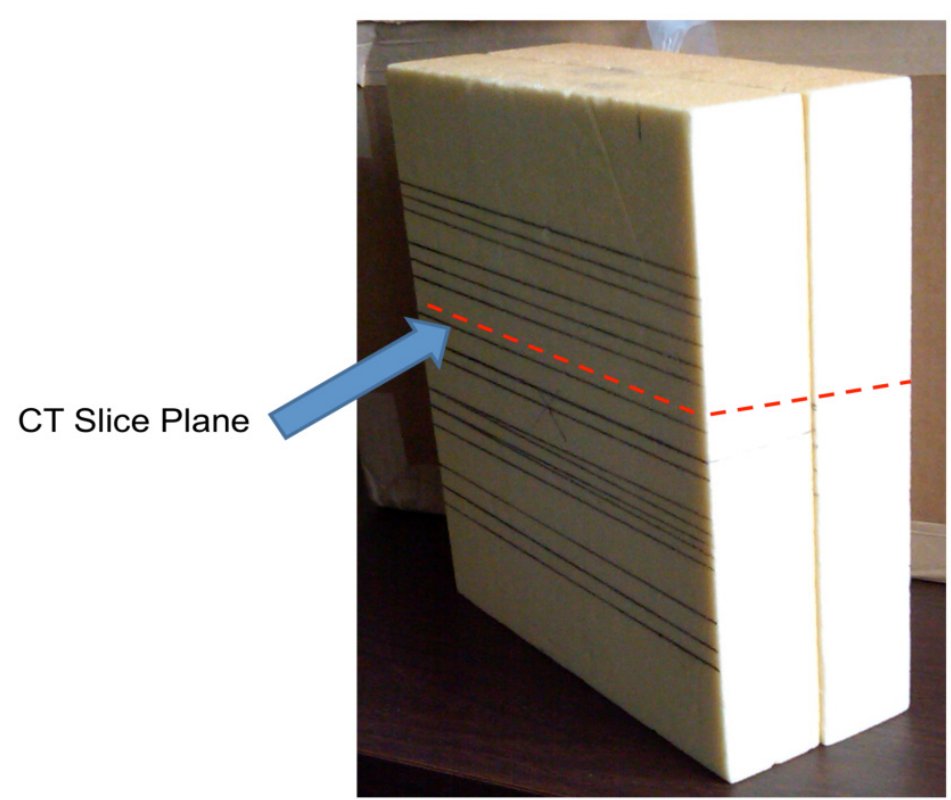

(b) Flat bottom hole sample sandwiched with a second piece of foam so holes are covered

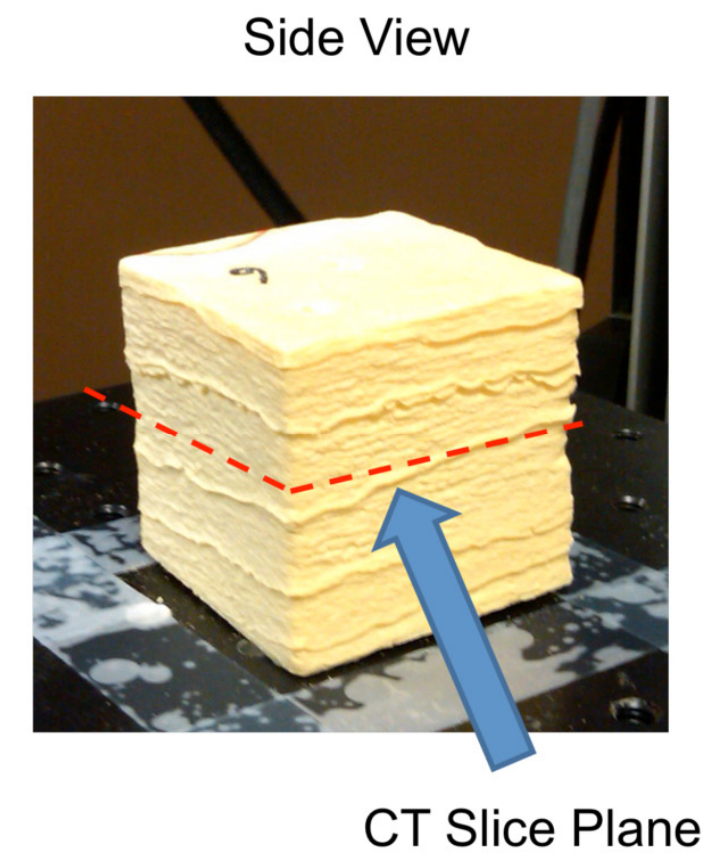

(c) Drilled hole sample

Top View

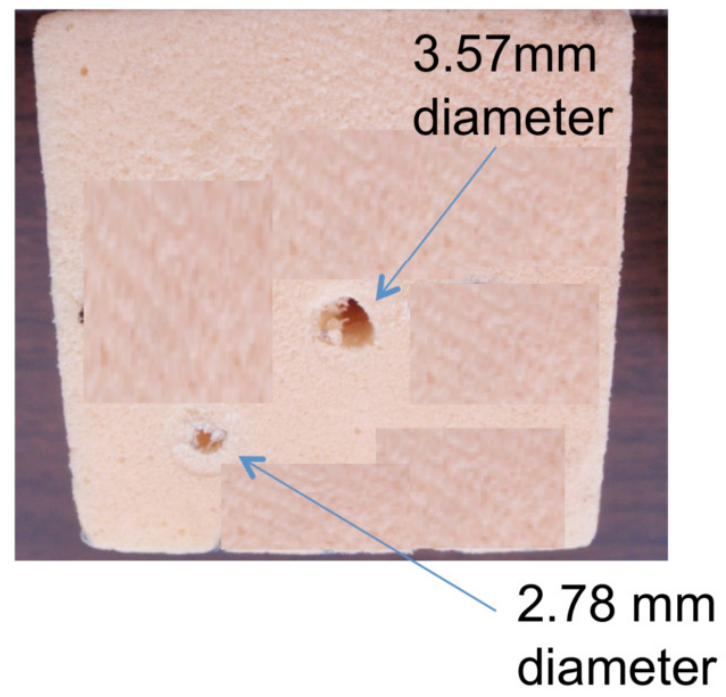

Figure 5.-Concluded. 
Another set of samples was fabricated with voids that are thought to more closely simulate naturallyoccurring voids. The voids in these samples were completely embedded in the pieces of foam and a marker was used to mark their positions and morphology as determined from x-ray inspection. The samples inspected are shown in Figure 6.
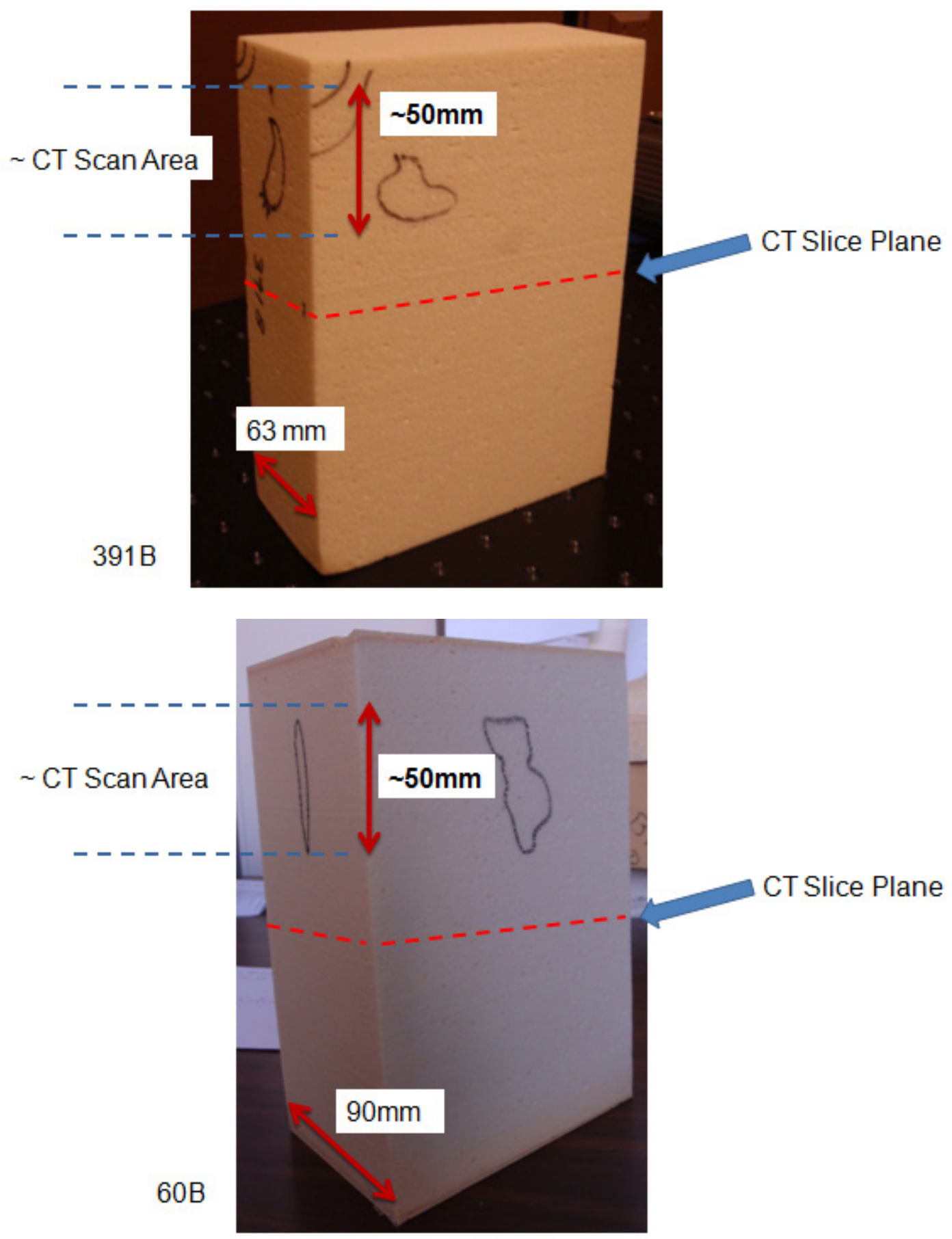

Figure 6.-Samples with voids simulating naturally-occurring voids. Black outlines show approximate position and morphology of the embedded void. 

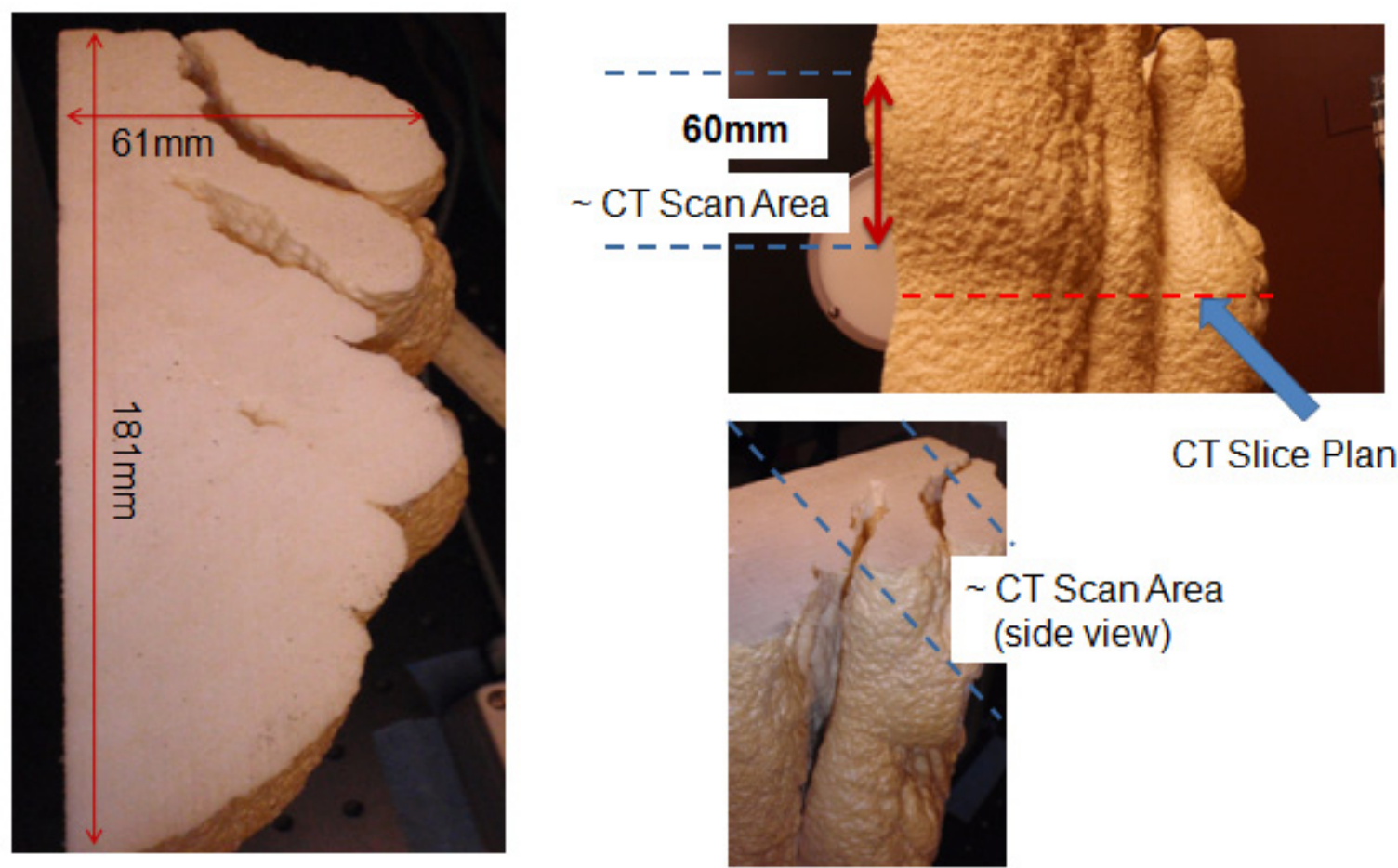

Figure 7.-SOFI corrugated foam sample.

TABLE 1.-SCAN INCREMENTS USED FOR THE VARIOUS SAMPLES

\begin{tabular}{|l|c|c|c|}
\hline $\begin{array}{l}\text { Foam sample/scan } \\
\text { increment }\end{array}$ & $\begin{array}{c}\mathrm{X}, \\
\mathrm{mm}\end{array}$ & $\begin{array}{c}\theta, \\
\text { degree }\end{array}$ & $\begin{array}{c}\mathrm{Z}, \\
\mathrm{mm}\end{array}$ \\
\hline $\begin{array}{l}\text { Flat bottom holes foam } \\
\text { sandwich sample }\end{array}$ & 0.3 & 1 & 1 \\
\hline Drilled holes sample & 0.3 & 1 & 2 \\
\hline Simulated void samples & 0.3 & 1 & 1.5 \\
\hline Corrugated sample & 0.3 & 1 & 2 \\
\hline
\end{tabular}

A third SOFI "corrugated" sample with no known voids but extraordinary external texture also underwent THz CT inspection and is shown in Figure 7.

\section{THz CT Experimental Procedure}

The samples were placed on a stage located centrally between the transmitter and receiver (Fig. 1(b)). The distance from the transmitter to the center of the object and from the transmitter to the receiver was 475 and $950 \mathrm{~mm}$, respectively. Table 1 shows the scan increments used for the various samples.

The $\mathrm{Z}$ scan increment for the $\mathrm{THz} \mathrm{CT}$ is a relatively coarse increment compared to the ultimate resolution in the $\mathrm{Z}$ direction for the $\mathrm{X}$-ray $\mathrm{CT}$, but it is approximately equal to the expected resolution for the THz CT method. Generally, 20 to 30 slices (XY plane) were obtained for one scan which encompassed one row of the voids for the flat bottom holes sample. For a $1^{\circ}$ angular scan increment, a chord of data is acquired in about 4s. Approximately 10 waveforms were averaged at each scan increment. A single slice of data with 100 to 150 chords would take several minutes to acquire. 


\section{Microfocus X-Ray CT Experimental Procedure}

Microfocus X-ray CT was performed on some samples in order to size the voids in the samples with embedded voids and also to directly compare the results from $\mathrm{THz}$ CT to X-ray CT. The samples were placed on the stage of the CT system such that magnification was approximately 1.2 to 1.5 times. The CT system consists of a $200 \mathrm{keV}$ microfocus $\mathrm{x}$-ray source that produces a cone beam, a state-of-the-art cesium iodide solid state area detector, a 4-axis motion control unit with a 16 in. swing diameter, and a dedicated high-speed reconstruction workstation. The stage is rotated $360^{\circ}$ at sub- $1^{\circ}$ increments to create a complete set of projections. A fast Feldkamp reconstruction algorithm was employed to create the slice images from the projections. Input power for the foam samples was generally in the $80 \mathrm{keV}$ range providing a microfocus spot size in the 50 to $80 \mu \mathrm{m}$ range. Samples were scanned using a 2 by 2 pixel configuration. Resulting voxel dimension was in the $200 \mu \mathrm{m}$ range. Figure 8 shows a picture of the X-ray CT setup for one sample.

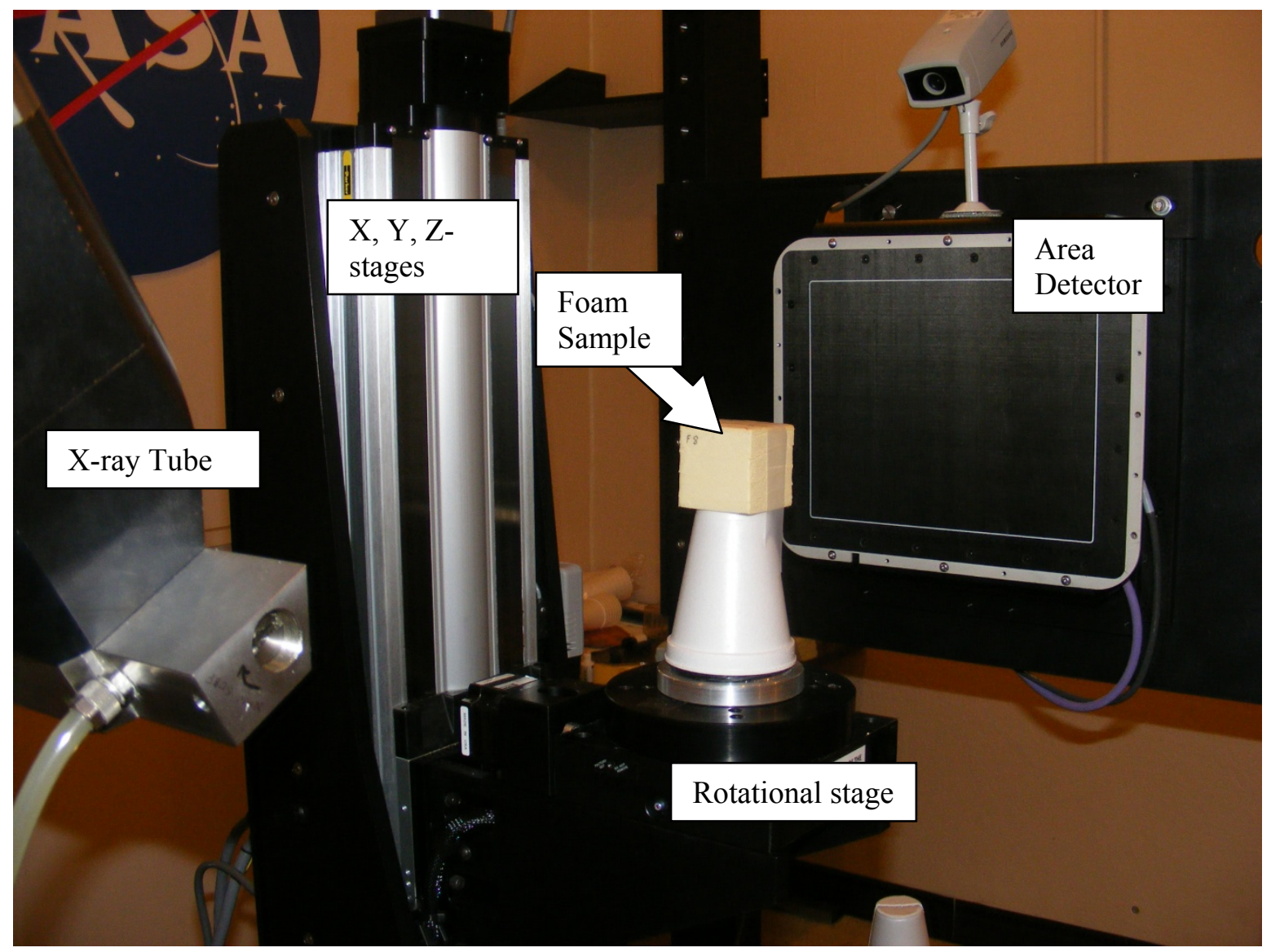

Figure 8.-X-ray CT experimental setup. 


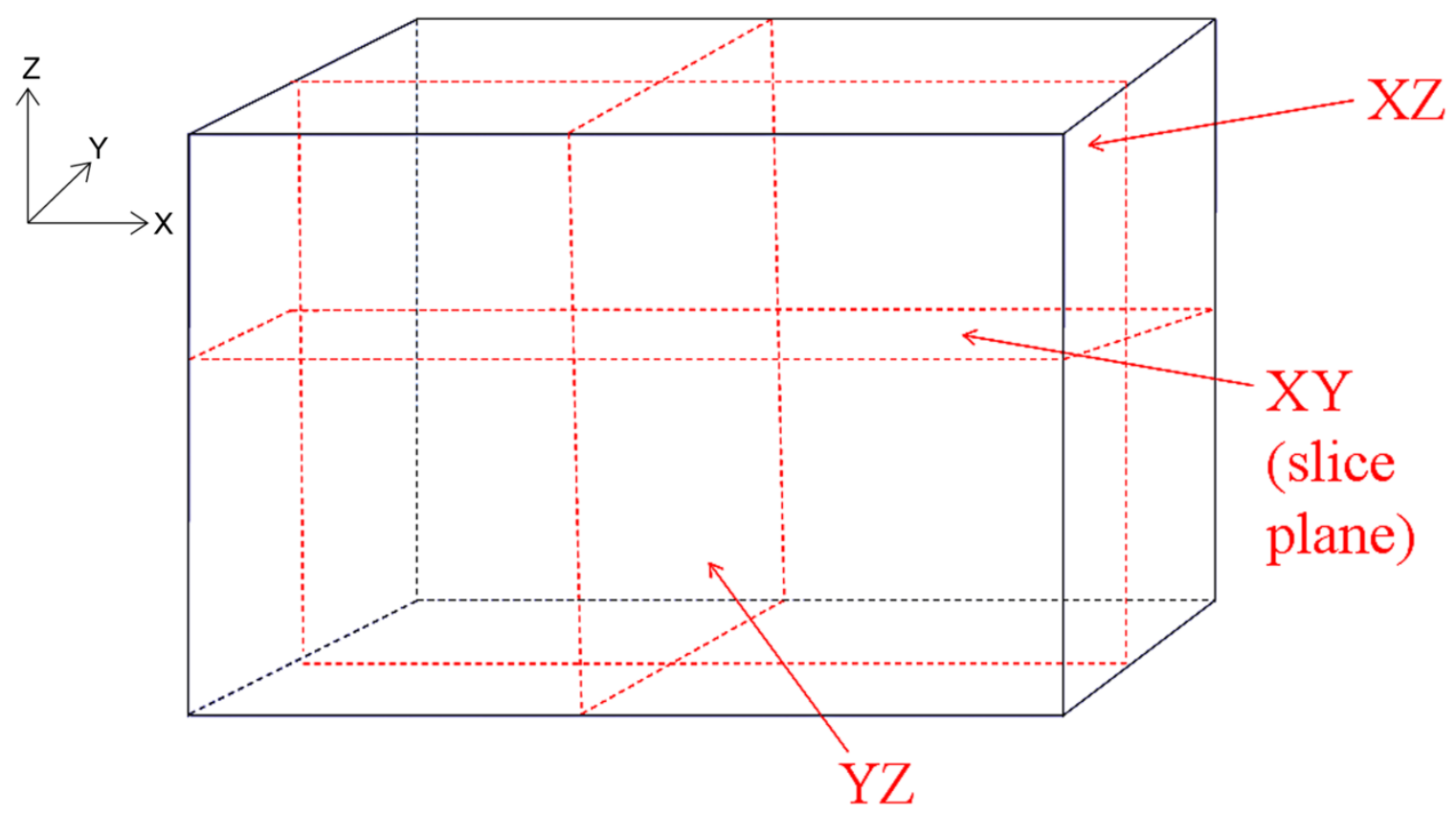

Figure 9.-XY, $X Z$, and $Y Z$ planes and their relationship to the CT slice plane.

\section{CT Data Presentation}

The presentation of CT data is best viewed in movie fashion where volume renderings can be rotated and slice views can be run through. This is not possible for literature so we present planar and volumetric views of the most important results. Figure 9 shows the definitions of the slice view planes and their relation to the CT slice plane. Note that XY (top) view represents the slice plane or axial, view.

ILUMAVision software (Ref. 13), which is a native component of the Hytec X-ray CT system, was used to visualize both the $\mathrm{x}$-ray and $\mathrm{THz} \mathrm{CT}$ data. Prior to rendering, the images obtained from the THz CT system were filtered (faulty data slices removed), cropped, and rotated as needed using the NDE Wave \& Image Processor (NDEWIP) software (Refs. 14 and 15). A fourier interpolation procedure to artificially increase the number of slices to between 80 and 140 was performed in NDEWIP. The image set was then saved in a binary format required (Ref. 16) using NDEWIP to allow planar and volume rendering display using ILUMAVision software. The user of ILUMAVision software can create custom color tables and adjust the level of transparency for the volume renderings, and the settings for these are subjective. The resultant voxels of the $\mathrm{THz} \mathrm{CT}$ renderings are group index of refraction values for the material within the voxel.

\section{Results}

Figure 10 shows top (XY), side views (XZ and $\mathrm{YZ}$ ) and a semi-transparent volume rendering for a $\mathrm{THz}$ CT slice set for the row of flat bottom holes of diameter $=6.35 \mathrm{~mm}$ (smallest diameter holes) with the sample placed on the stage as shown in Figure 1(b). The focus was approximately at the center of the sample. With large samples such as this, as previously discussed, it is expected that the resolution would degrade noticeably towards the outer edges. The hole depths at 6,9,12, and 15 percent of material thickness (with respect to the [Y] direction of the THz beam with the sample mounted as shown in Figure 1(b)) were clearly revealed with nominal contrast enhancement. The hole depth at 3 percent of material thickness could only be observed with significant contrast expansion and resulted in enhancement of artifacts as well. Thus, hole depths likely need to be around 6 percent of thickness or greater in the direction of the terahertz beam for unambiguous detectability. The slice positions chosen to display are related to each other and are demarcated by the horizontal and vertical cursor positions in the slice view images. For example, in the XZ 
side view image, the horizontal cursor is located approximately mid-way through the sample section, and the top view shown below it corresponds to the top view section at this horizontal location. A line profile of gray value versus position at the location of the horizontal line on the $\mathrm{XZ}$ view in Figure 10 is shown in Figure 11 and clearly reveals four indications.

Figure 12 shows top (XY), side views (XZ and $\mathrm{YZ}$ ) and a semi-transparent volume rendering for a $\mathrm{THz}$ CT slice set for the row of flat bottom holes of diameter $=19.05 \mathrm{~mm}$ (largest diameter holes). Note that this sample was remounted upside down so the stage fastening hardware would not interfere with the $\mathrm{THz}$ beam. The hole depths at $6,9,12$, and 15 percent of material thickness were clearly revealed with nominal contrast enhancement. The hole depth at 3 percent of material thickness could still only be observed with significant contrast expansion and resulted in enhancement of artifacts as well. A line profile of gray value versus position at the location of the horizontal line on the XZ view in Figure 12 is shown in Figure 13 and clearly reveals four indications.
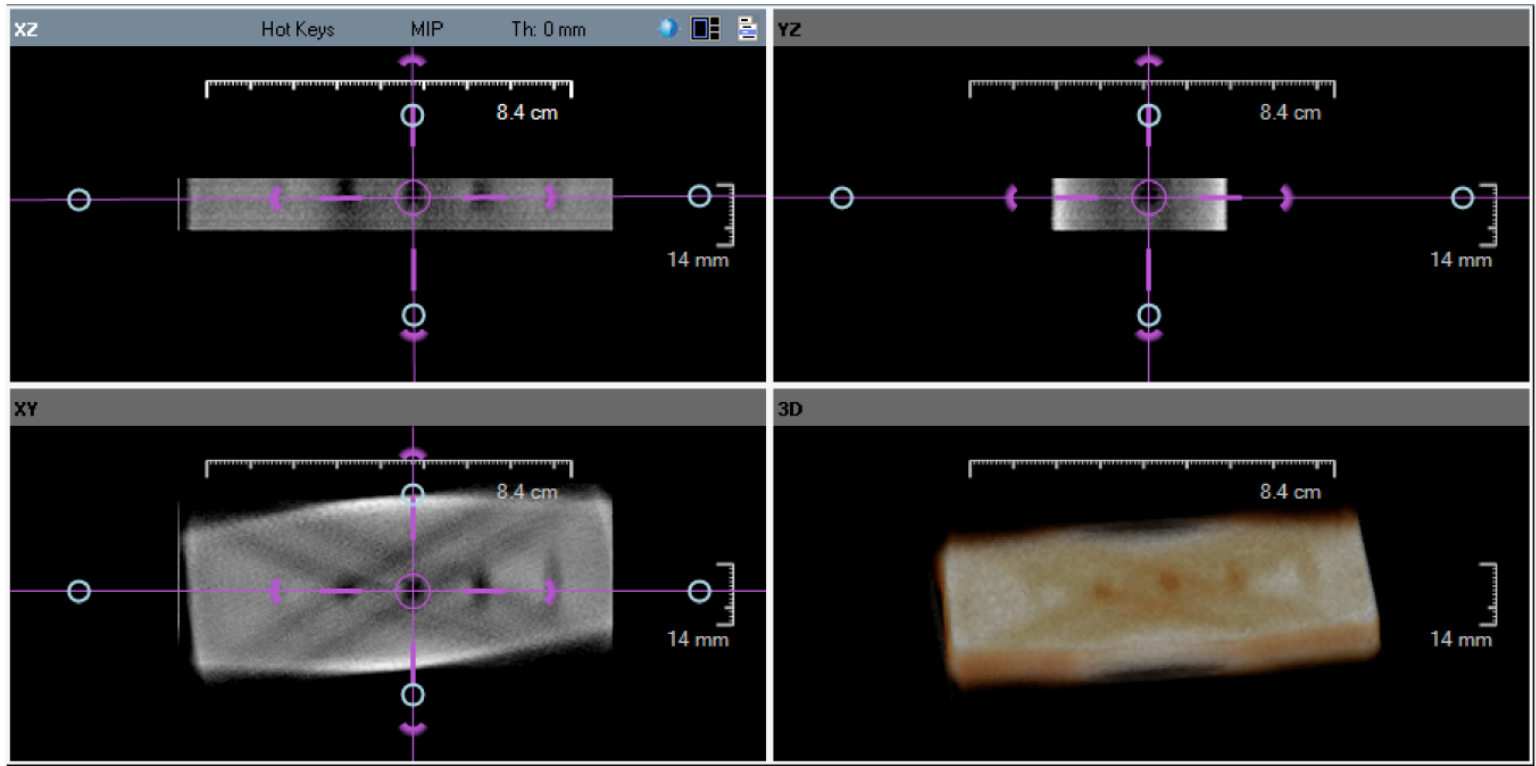

Figure 10.-Top $(X Y)$, side views $(X Z$ and $Y Z)$ and a semi-transparent volume rendering for a THz CT slice set for the row of flat bottom holes of diameter $=6.35 \mathrm{~mm}$. X-like feature is CT reconstruction artifact.

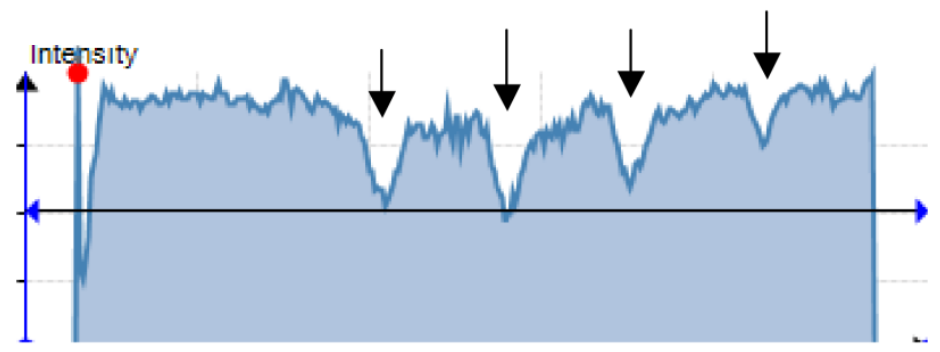

Figure 11.- Line profile of gray value versus position at the location of the horizontal line on the $X Z$ view in Figure 10 indicating that four of the holes (as indicated by the arrows pointing at the valleys) are clearly revealed. 

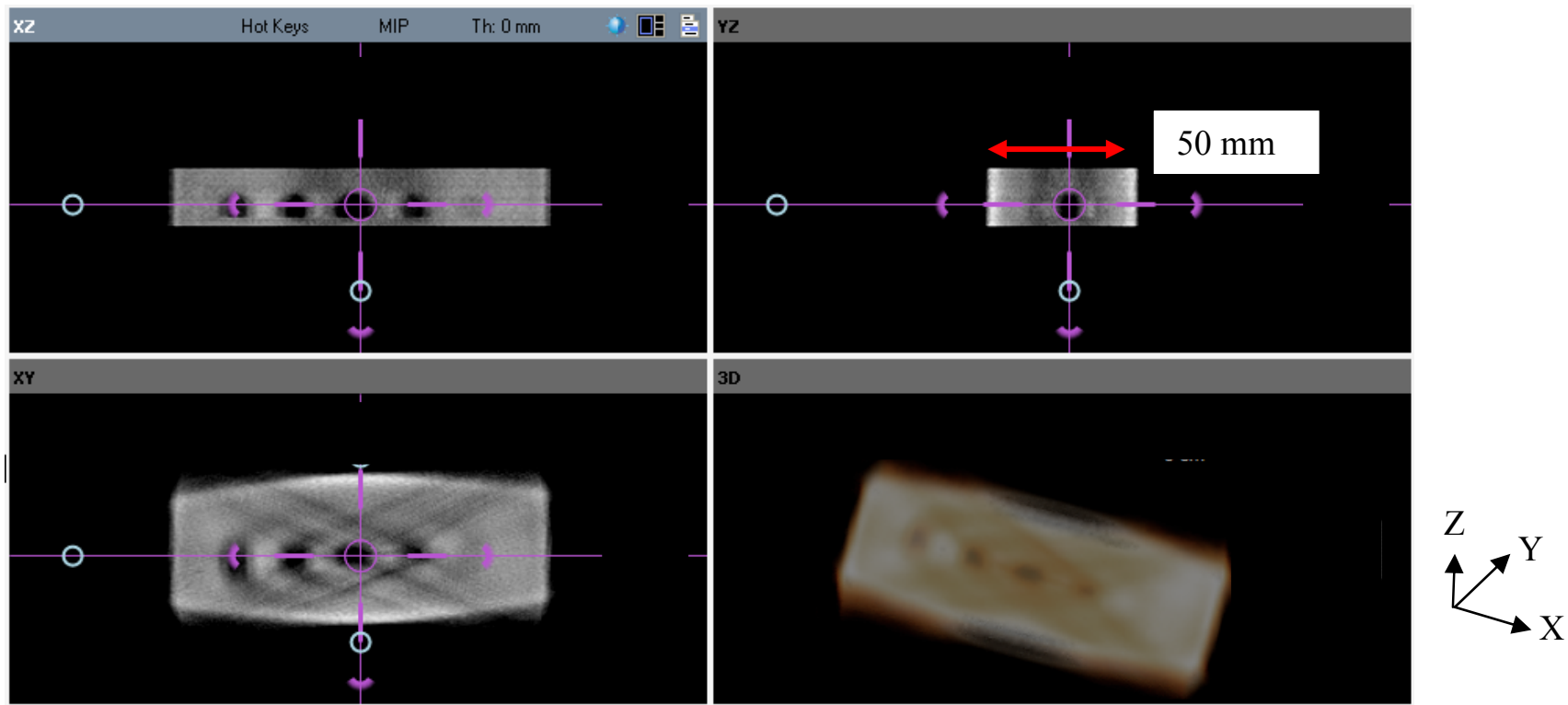

Figure 12.-Top (XY), side views ( $X Z$ and $Y Z)$ and a semi-transparent volume rendering for a THz CT slice set for the row of flat bottom holes of diameter $=19.05 \mathrm{~mm}$. $X$-like feature is $\mathrm{CT}$ reconstruction artifact.

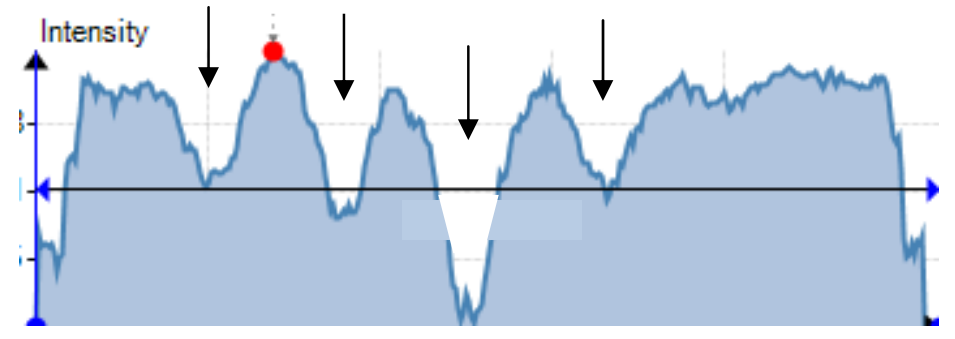

Figure 13.-Line profile of gray value versus position at the location of the horizontal line on the $X Z$ view in Figure 12 indicating that four of the holes (as indicated by the arrows pointing at the valleys) are clearly revealed. 
Figures 14(a) and (b) show top (XY), side views (XZ and YZ) and semi-transparent volume renderings for X-ray CT and THz CT slice sets for a section of the sample containing two drilled holes. Horizontal and vertical cursors are removed from these images for clarity. The side slice views are shown for the $3.57 \mathrm{~mm}$ diameter drilled hole. For the $\mathrm{THz} \mathrm{CT}$, the $\mathrm{X}$ scan increment, angular scan increment, and $\mathrm{Z}$ scan increment were $0.3 \mathrm{~mm}, 1^{\circ}$, and $2.0 \mathrm{~mm}$, respectively. Both holes are detected although the $2.78 \mathrm{~mm}$ diameter hole is less prominent than the hole. It can be concluded that the limit of clear detectability is probably being approached for the $2.78 \mathrm{~mm}$ diameter hole. The $\mathrm{THz}$ images as expected provide a diffuse lower resolution view of the drilled holes as compared to the X-ray CT images. The additional line-like indications in the $\mathrm{X}$-ray CT image are lines showing where a new layer of foam began to be sprayed.
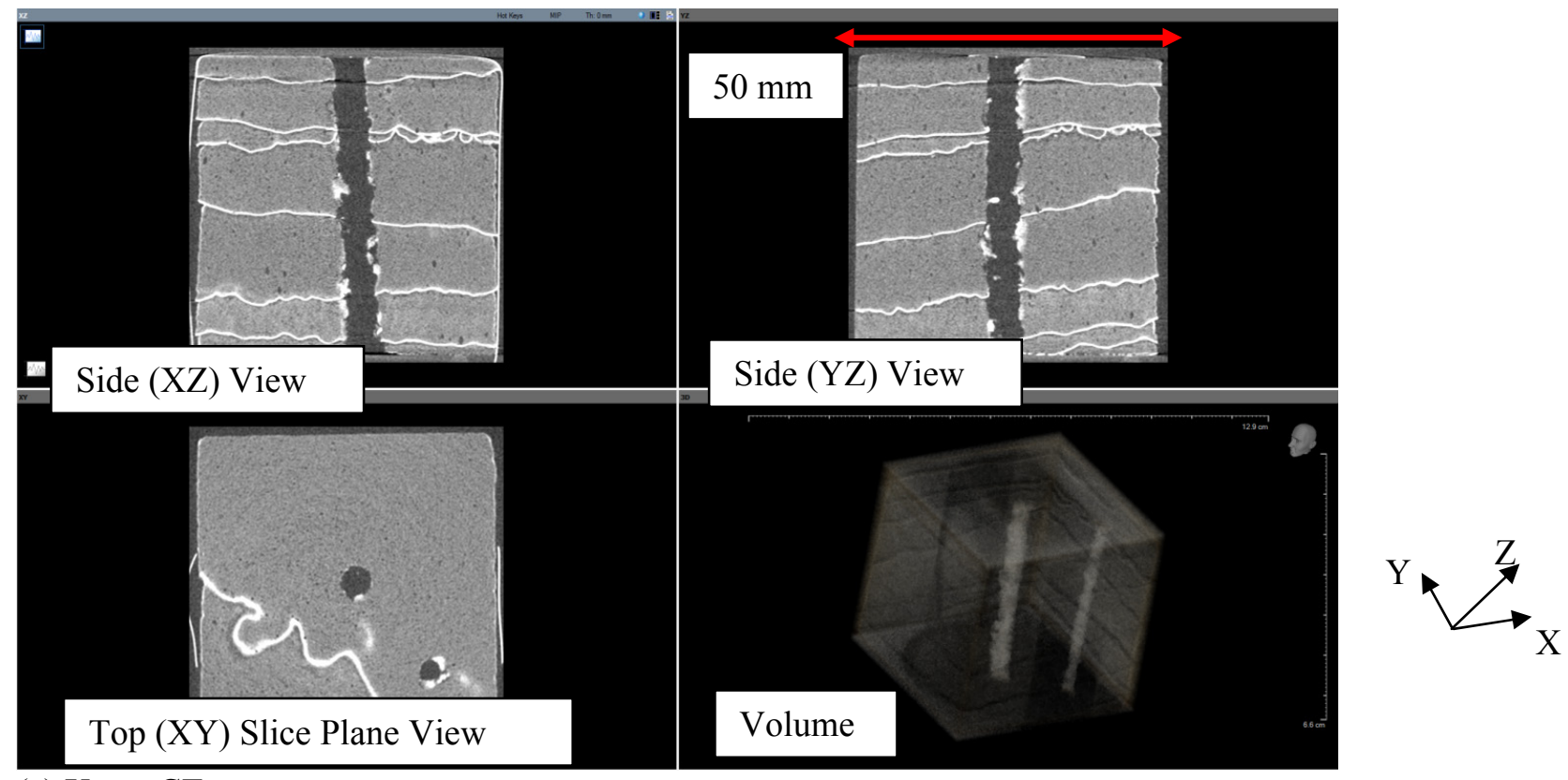

(a) X-ray CT
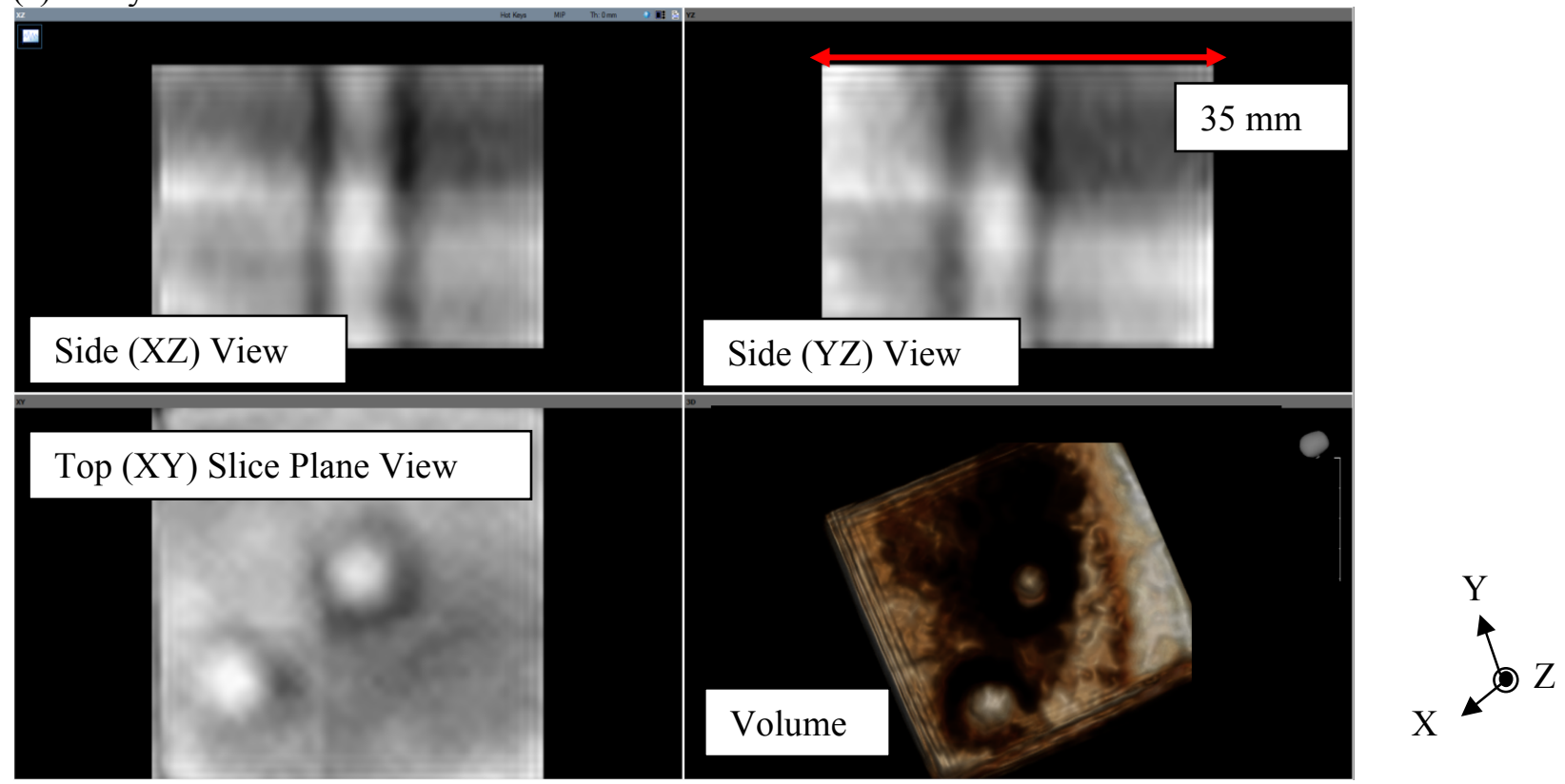

(b) THz CT (cropped)

Figure 14.- - Top $(X Y)$, side views ( $X Z$ and $Y Z$ ) and a semi-transparent volume rendering for a

CT slice set for a section of the sample with drilled holes. 
Figures 15(a) and (b) show top (XY), side views (XZ and YZ) and semi-transparent volume renderings for X-ray CT and THz CT slice sets for a section of the sample 391B containing an embedded void. For the $\mathrm{THz} \mathrm{CT}$, the $\mathrm{X}$ scan increment, angular scan increment, and $\mathrm{Z}$ scan increment were $0.3 \mathrm{~mm}, 1^{\circ}$, and $1.5 \mathrm{~mm}$, respectively. The $\mathrm{THz} \mathrm{CT}$ easily detects the void in the various planar views, and the $\mathrm{THz} \mathrm{CT}$ volume rendering of the void compares favorably with the X-ray CT volume rendering. The THz images as expected provide a diffuse lower resolution view of the void as compared to the X-ray CT images. Linear indications on the $\mathrm{THz} \mathrm{CT}$ images are artifacts of the $\mathrm{THz} \mathrm{CT}$ process. The X-ray $\mathrm{CT}$ images also reveal significant smaller numbers of smaller pores in the foam that are not revealed by the THz CT images.
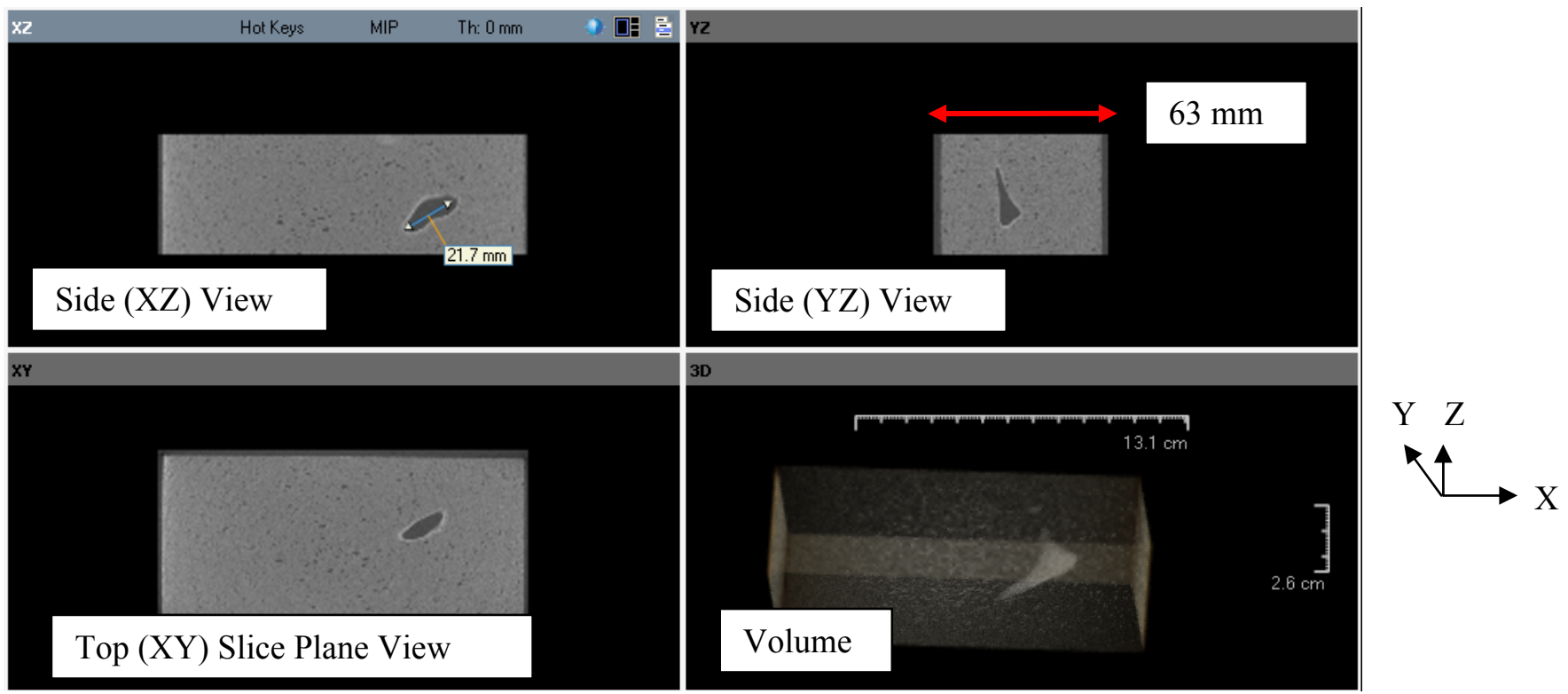

(a) X-ray CT
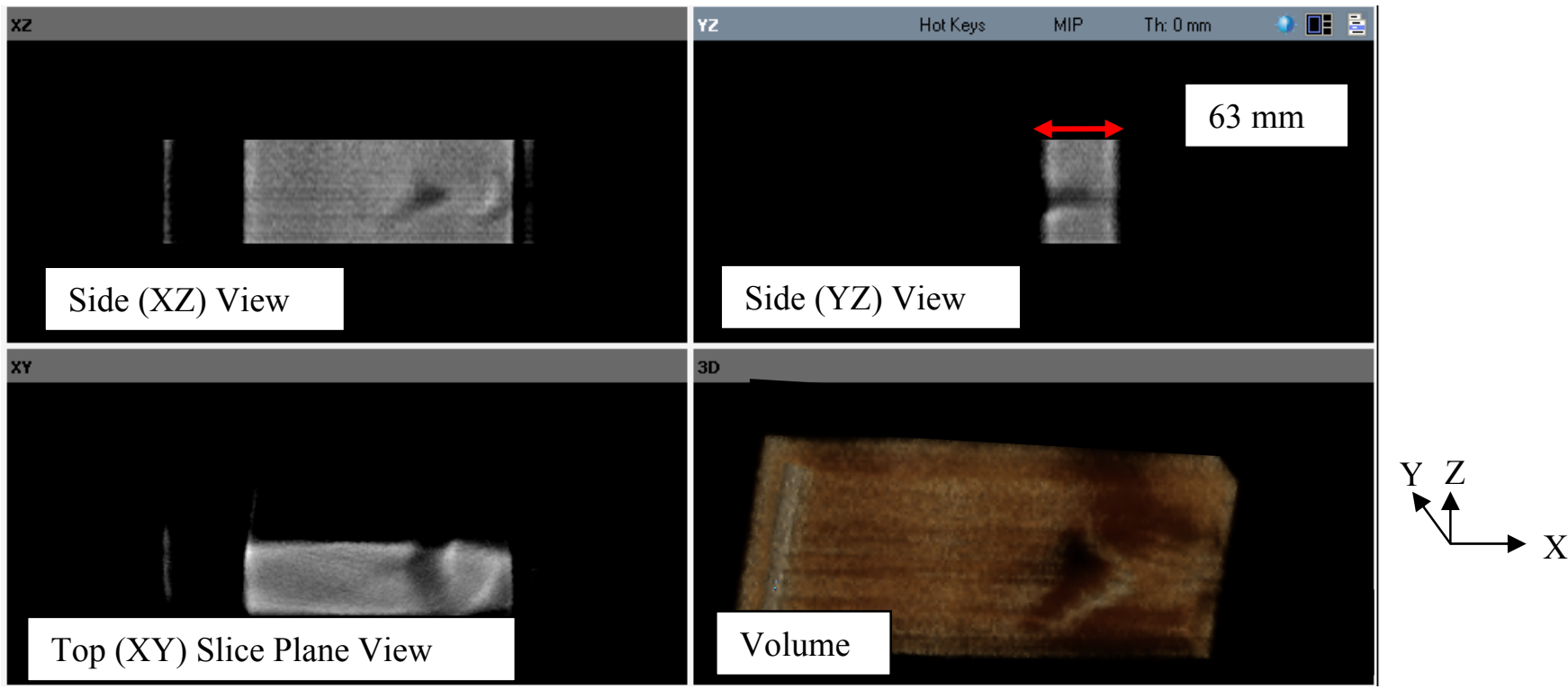

(b) $\mathrm{THz} \mathrm{CT}$

Figure 15.-Top (XY), side views ( $X Z$ and $Y Z)$ and a semi-transparent volume rendering for a CT slice set for a section of the sample 391B containing an embedded void. 
Figures 16(a) and (b) show top (XY), side views (XZ and YZ) and semi-transparent volume renderings for X-ray $\mathrm{CT}$ and $\mathrm{THz} \mathrm{CT}$ slice sets for a section of the sample 60B containing an embedded void. For the $\mathrm{THz} \mathrm{CT}$, the $\mathrm{X}$ scan increment, angular scan increment, and $\mathrm{Z}$ scan increment were $0.3 \mathrm{~mm}$, $1^{\circ}$, and $1.5 \mathrm{~mm}$, respectively. The THz CT easily detects the void in the various planar views. The $\mathrm{THz}$ $\mathrm{CT}$ volume rendering of the void has a shape that resembles that shown in X-ray CT volume rendering, and is seen in more detail in the multiple views shown in Figure 17
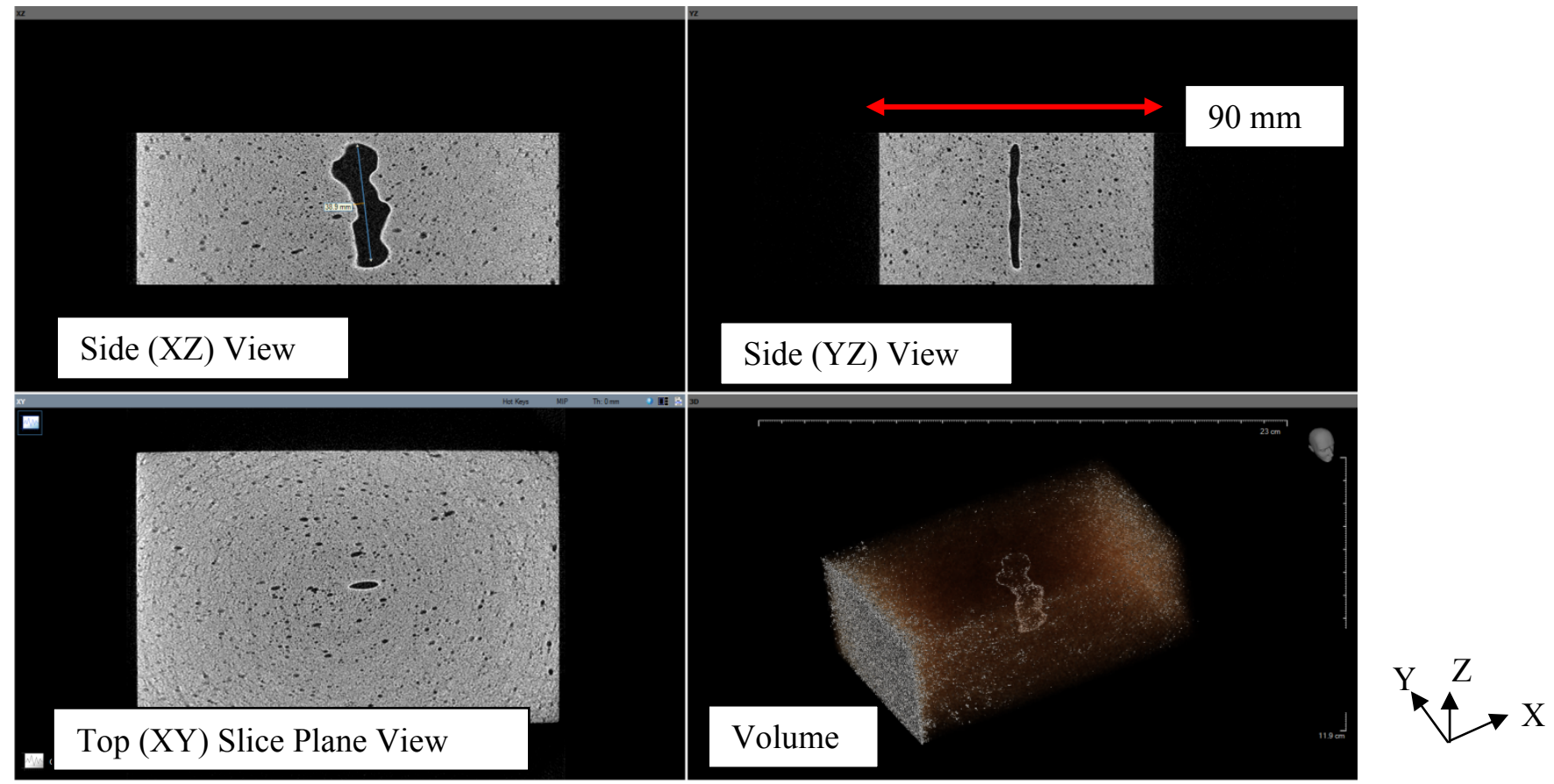

(a) X-ray CT.
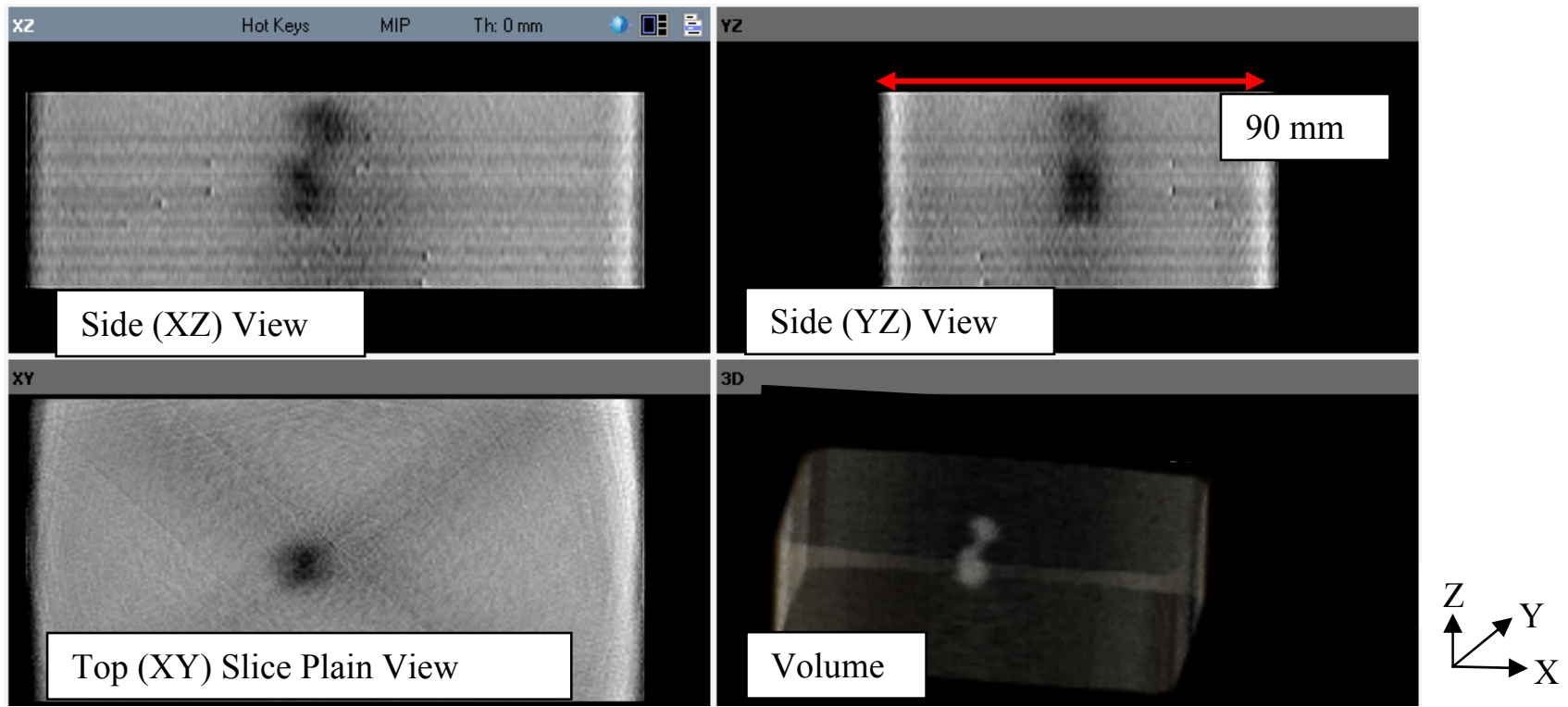

(b) $\mathrm{THz}$ CT.

Figure 16.-Top $(X Y)$, side views $(X Z$ and $Y Z)$ and a semi-transparent volume rendering for a $C T$ slice set for a section of the sample $60 \mathrm{~B}$ containing an embedded void. 


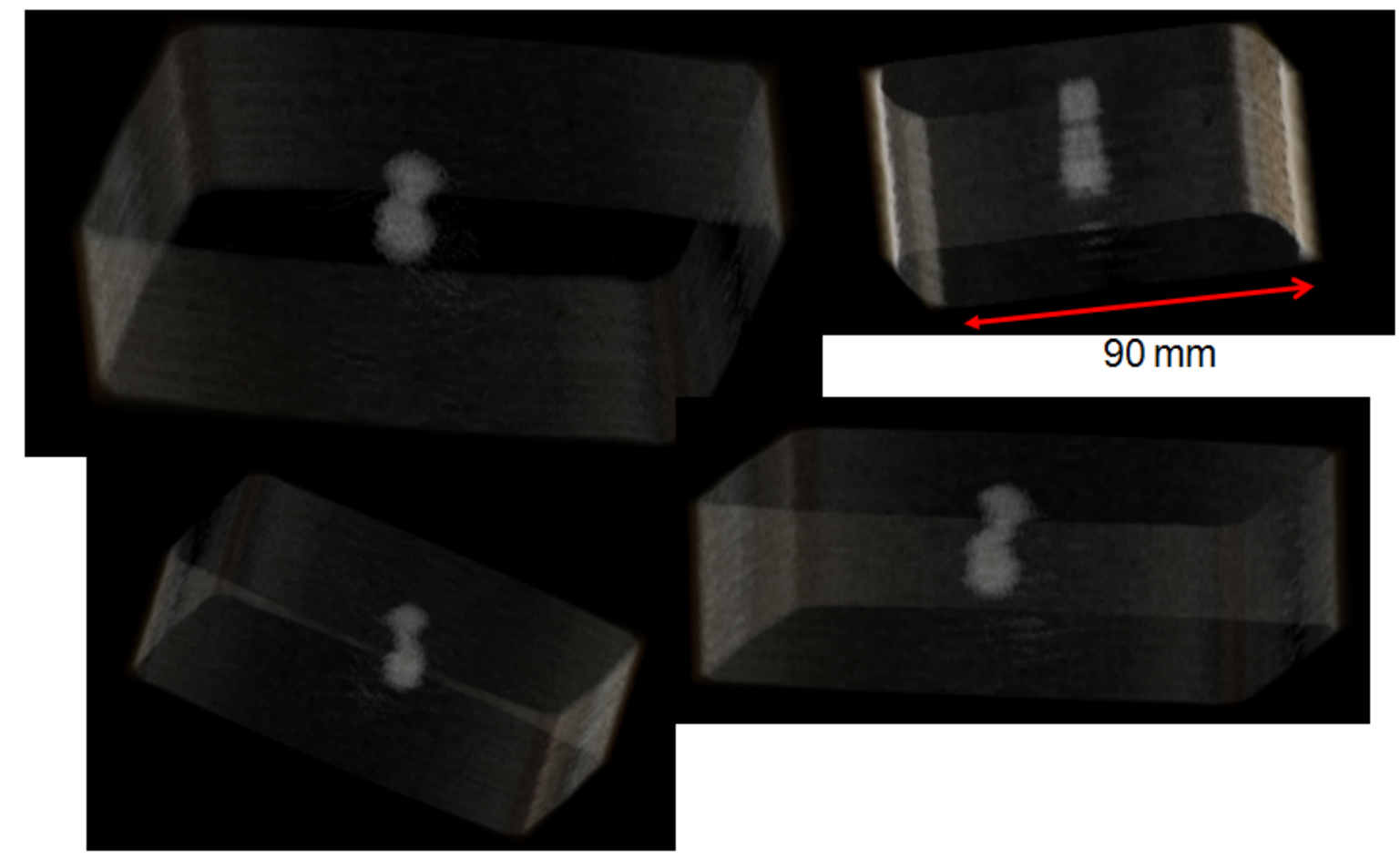

Figure 17.-Several semi-transparent views of a $\mathrm{THz}$ CT volume rendering for a section of sample 60B. 
Figures 18(a) and (b) show top (XY), side views (XZ and YZ) and semi-transparent and opaque volume renderings for X-ray CT and $\mathrm{THz}$ CT slice sets for a section of the corrugated foam sample. Opaque renderings are also shown since the exterior details are of primary concern for this sample. For the $\mathrm{THz} \mathrm{CT}$, the $\mathrm{X}$ scan increment, angular scan increment, and $\mathrm{Z}$ scan increment were $0.3 \mathrm{~mm}, 1^{\circ}$, and $2.0 \mathrm{~mm}$, respectively. The volumetric renderings from both methods show the same overall shape. As expected and as for the prior results, the details of the exterior are clearly resolved in the X-ray CT views but not the $\mathrm{THz} \mathrm{CT}$ views.

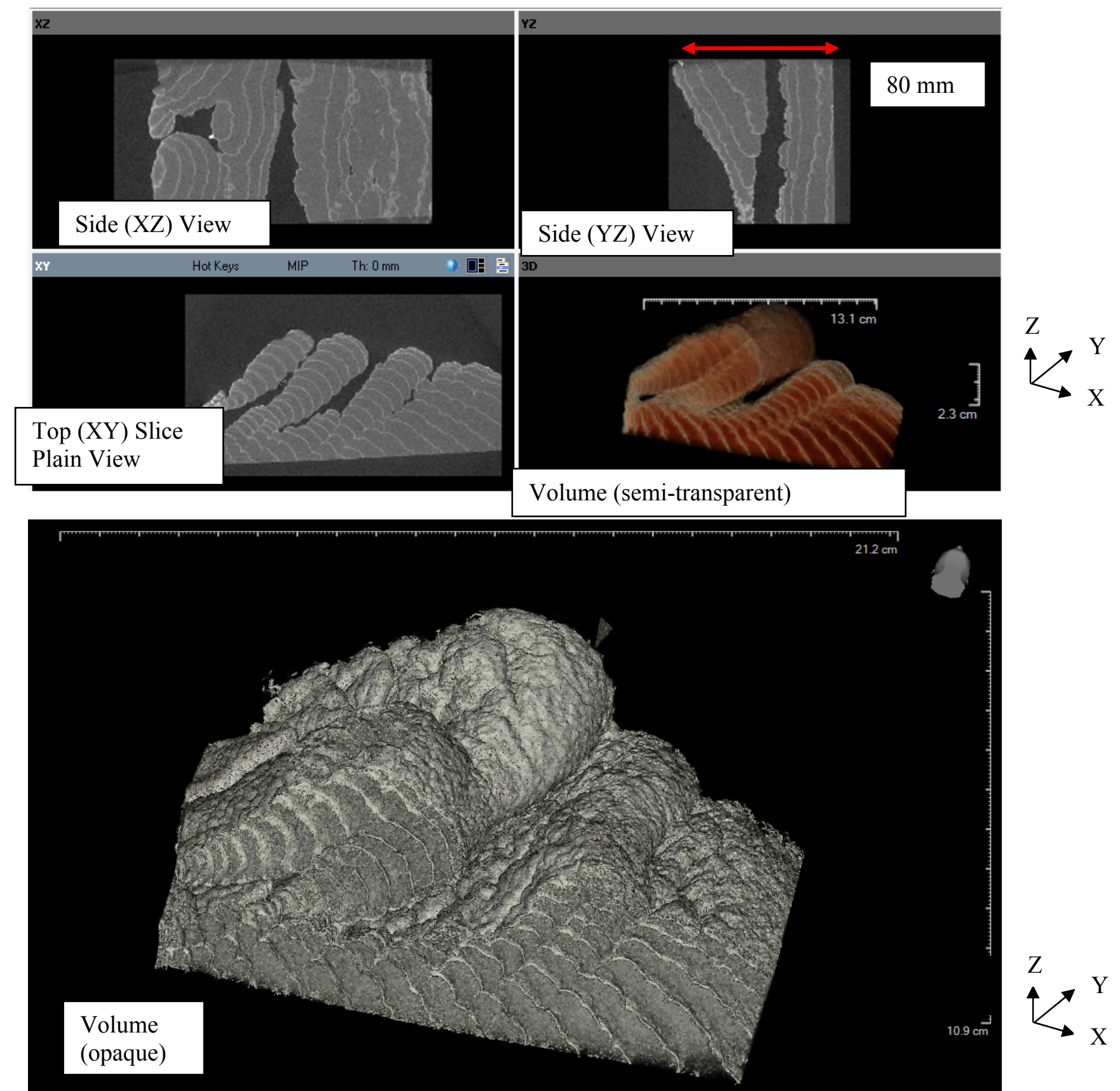

(a) X-ray CT (including semi-transparent and opaque volume representations)

Figure 18.-Top $(X Y)$, side views $(X Z$ and $Y Z)$ and semi-transparent and opaque volume renderings for a $C T$ slice set for the corrugated foam sample. 

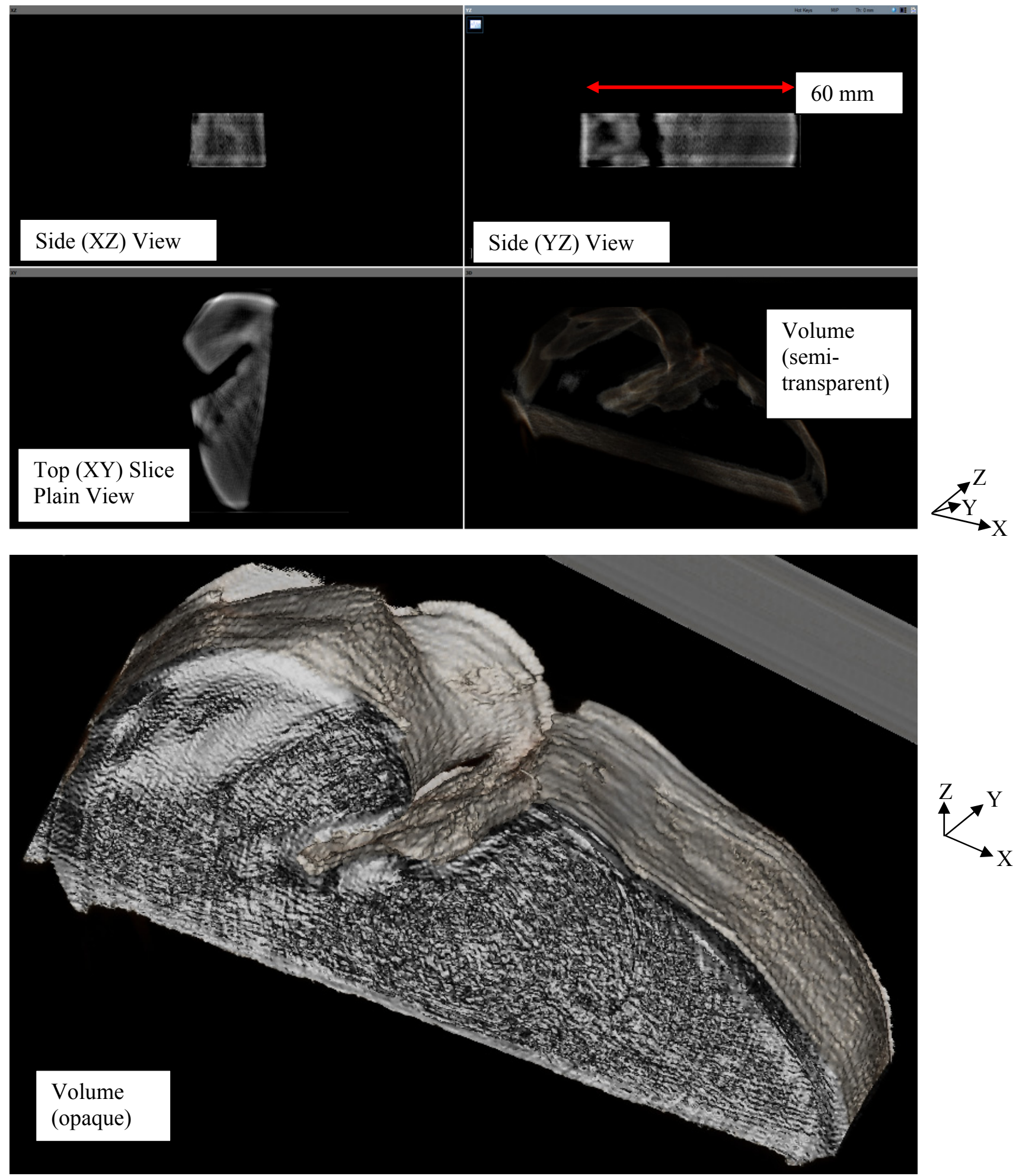

(b) $\mathrm{THz} \mathrm{CT}$

Figure 18.-Concluded. 


\section{Conclusions and Future Work}

A terahertz axial computed tomography system has been developed that uses time domain measurements in order to form cross-sectional image slices and three-dimensional volume renderings of THz-transparent materials. The system can inspect samples as large as $0.0283 \mathrm{~m}^{3}\left(1 \mathrm{ft}^{3}\right)$. The system utilizes one transmitter and one receiver, and the sample is rotated $360^{\circ}$ to obtain sinogram information. In this study, the system was evaluated for its ability to detect and characterize flat bottom holes, drilled holes, and embedded voids in foam materials utilized as thermal protection on the external fuel tanks for the Space Shuttle. THz CT was able to detect voids less than $3 \mathrm{~mm}$ in diameter but hole depths likely need to be around 6 percent of thickness or greater in the direction of the terahertz beam for unambiguous detectability. Embedded irregularly-shaped voids simulating naturally-occurring voids approximately 10 to $50 \mathrm{~mm}$ in dimension were clearly detected by THz CT. A foam sample with significant external texture had its general shape reasonably well-defined by THz CT. As expected, THz CT provided less sharp (more diffuse) views of internal features and topography as compared to x-ray micro-computed tomography results. Artifacts are present in current reconstruction methods (this is also true for X-ray CT but X-ray CT reconstruction artifact removal is at an advanced stage).

Further work can be envisioned that includes lens systems that result in a smaller beam diameter, linear and area detector array-based systems development, a combined two-dimensional reflection and transmission mode CT system, improvements in data acquisition such as a 64-bit operating system to allow larger data set acquisition and speed enhancements. The use of different wave parameters for the CT measurement including spectral analysis to obtain results as a function of frequency is also planned. Additionally, the use of this technology to characterize thermal protection system (TPS) materials under development is of interest to NASA.

For $\mathrm{THz}$ methods, there are no radiation safety issues at low power as there are for x-ray methods. If critical flaw sizes are in the several $\mathrm{mm}$ or larger range, it can be envisioned that a combined twodimensional reflection and transmission mode CT system could play a role in future inspections for NASA. Consider that the two-dimensional reflection mode portion can provide a rapid scan of asfabricated sections of TPS to determine if flaws exist. If flaws are found, the same instrument in threedimensional CT mode can provide more detailed morphological information with no safety concerns.

\section{References}

1. "Sensing with Terahertz Radiation," D.M. Mittleman, ed., Springer, 2003.

2. Arnone D.D., Ciesla C.M., Corchia A., Egusa S., Pepper M., Chamberlain J.M., Bezant C., Linfield E.H., Clothier R. and Khammo N. Application of terahertz (THz) technology to medical imaging. In Proc. SPIE Terahertz Spectroscopy Applications II; International Society for Optical Engineering: Bellingham, WA, 1999; pp. 209-219.

3. Mittleman, D.M., Gupta, M., Neelamani, R., Baraniuk, R.G., Rudd, J.V. and Koch, M. "Recent Advances in Terahertz Imaging," App. Phys. B, 68, 1085 (1999).

4. Dorney, T., Symes, W., Baraniuk, R.G., and Mittleman, D., "Terahertz multistatic reflection imaging," J. Opt.Soc. Am. A, 19, 1432-1442 (2002).

5. Zimdars, D., Valdmanis, J.A., White, J.S., Stuk, G., Williamson, S., Winfree, W.P. and Madaras, E.I. "Technology and Applications of Terahertz Imaging Non Destructive Examination: Inspection of Space Shuttle Sprayed on Foam Insulation," Review of Quant. Non Destructive Evaluation Vol. 24, ed. D.O. Thompson and D.E. Chimenti, 570-7 (2005).

6. Mittleman, D.M., Jacobsen, R.H., and Nuss, M.C., “T-Ray Imaging,” IEEE J. Sel. Top. Quant. Elec., 2, 679 (1996).

7. Roth, D.J., Seebo, J.P., and Winfree, W.P., "Simultaneous Noncontact Precision Imaging of Microstructural and Thickness Variation in Dielectric Materials Using Terahertz Energy," Materials Evaluation, Vol. 66, No. 3, March 2008. 
8. Zimdars, D., Duling, I., Fichter, G., and White, J., "Production Process Monitoring of Multilayered Materials Using Time-Domain Terahertz Guages," Review of Quant. Non Destructive Evaluation Vol. 29A, ed. D.O. Thompson and D.E. Chimenti, 564-571 (2009).

9. Mittleman, D.M., Hunsche, S., Boivan, L. and Nuss, M.C., "T-Ray Tomography," Opt. Lett., 22, 904 (1997).

10. Wang, S. and Zhang, X.-C., "Pulsed terahertz tomography,” Topical Review. J. Phys. D: Appl. Phys. 37 (2004).

11. Siegman, A.E., Lasers, pg 663-672 (University Science Books, Sausalito, CA 1986).

12. Herman, G.T. (2009), Fundamentals of Computerized Tomography: Image Reconstruction from Projections, 2nd Edition, Springer, ISBN 978-1-85233-617-2.

13. ILUMAVision Industrial ${ }^{\mathrm{TM}}$ Getting Started Guide, Document 1.0.1, IMTEC Corporation. 2008.

14. Roth, D.J., "Demonstration of an NDE Post-Processing Software Tool Developed at NASA Glenn Research Center," Presentation and Proceedings of ASNT Fall 07, November 12-16, Las Vegas, NV.

15. D.J. Roth, NDE Wave \& Image Processor Software User Manual, v3.0, 2010.

16. FlashCT Data File Format Specification Manual, Version 3.1. IMTEC Corporation. 2007. 


\begin{tabular}{|c|c|c|}
\hline \multicolumn{2}{|c|}{ REPORT DOCUMENTATION PAGE } & $\begin{array}{l}\text { Form Approved } \\
\text { OMB No. 0704-0188 }\end{array}$ \\
\hline \multicolumn{3}{|c|}{ 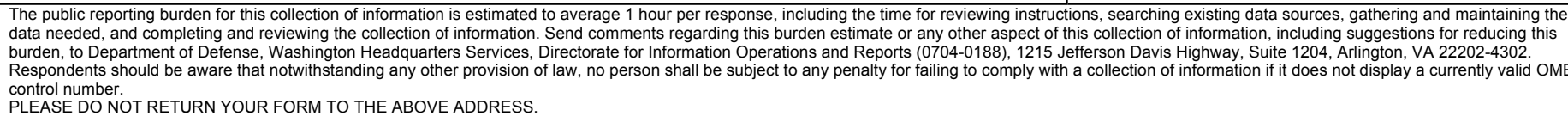 } \\
\hline $\begin{array}{l}\text { 1. REPORT DATE (DD-MM-YYYY) } \\
01-03-2011\end{array}$ & $\begin{array}{l}\text { 2. REPORT TYPE } \\
\text { Technical Memorandum }\end{array}$ & 3. DATES COVERED (From - To) \\
\hline \multirow{3}{*}{\multicolumn{2}{|c|}{$\begin{array}{l}\text { 4. TITLE AND SUBTITLE } \\
\text { Terahertz Computed Tomography of NASA Thermal Protection System Materials }\end{array}$}} & 5a. CONTRACT NUMBER \\
\hline & & 5b. GRANT NUMBER \\
\hline & & 5c. PROGRAM ELEMENT NUMBER \\
\hline \multirow{3}{*}{\multicolumn{2}{|c|}{$\begin{array}{l}\text { 6. AUTHOR(S) } \\
\text { Roth, D., J.; Reyes-Rodriguez, S.; Zimdars, D., A.; Rauser, R., W.; Ussery, W., W. }\end{array}$}} & 5d. PROJECT NUMBER \\
\hline & & 5e. TASK NUMBER \\
\hline & & $\begin{array}{l}\text { 5f. WORK UNIT NUMBER } \\
\text { WBS } 869021.03 .03 .01 .08\end{array}$ \\
\hline \multicolumn{2}{|c|}{$\begin{array}{l}\text { 7. PERFORMING ORGANIZATION NAME(S) AND ADDRESS(ES) } \\
\text { National Aeronautics and Space Administration } \\
\text { John H. Glenn Research Center at Lewis Field } \\
\text { Cleveland, Ohio 44135-3191 }\end{array}$} & $\begin{array}{l}\text { 8. PERFORMING ORGANIZATION } \\
\text { REPORT NUMBER } \\
\text { E-17623 }\end{array}$ \\
\hline \multirow{2}{*}{\multicolumn{2}{|c|}{$\begin{array}{l}\text { 9. SPONSORING/MONITORING AGENCY NAME(S) AND ADDRESS(ES) } \\
\text { National Aeronautics and Space Administration } \\
\text { Washington, DC 20546-0001 }\end{array}$}} & $\begin{array}{l}\text { 10. SPONSORING/MONITOR'S } \\
\text { ACRONYM(S) } \\
\text { NASA }\end{array}$ \\
\hline & & $\begin{array}{l}\text { 11. SPONSORING/MONITORING } \\
\text { REPORT NUMBER } \\
\text { NASA/TM-2011-216982 }\end{array}$ \\
\hline \multicolumn{3}{|c|}{$\begin{array}{l}\text { 12. DISTRIBUTION/AVAILABILITY STATEMENT } \\
\text { Unclassified-Unlimited } \\
\text { Subject Categories: } 38 \text { and } 16 \\
\text { Available electronically at http://www.sti.nasa.gov } \\
\text { This publication is available from the NASA Center for AeroSpace Information, 443-757-5802 }\end{array}$} \\
\hline
\end{tabular}

\section{SUPPLEMENTARY NOTES}

\section{ABSTRACT}

A terahertz axial computed tomography system has been developed that uses time domain measurements in order to form cross-sectional image slices and three-dimensional volume renderings of terahertz-transparent materials. The system can inspect samples as large as 0.0283 $\mathrm{m}^{3}\left(1 \mathrm{ft}^{3}\right)$ with no safety concerns as for x-ray computed tomography. In this study, the system is evaluated for its ability to detect and characterize flat bottom holes, drilled holes, and embedded voids in foam materials utilized as thermal protection on the external fuel tanks for the Space Shuttle. X-ray micro-computed tomography was also performed on the samples to compare against the terahertz computed tomography results and better define embedded voids. Limits of detectability based on depth and size for the samples used in this study are loosely defined. Image sharpness and morphology characterization ability for terahertz computed tomography are qualitatively described.

\section{SUBJECT TERMS}

Nondestructive tests; X-ray inspection; Computer aided tomography; Terahertz

\begin{tabular}{|c|c|c|c|c|c|}
\hline \multicolumn{3}{|c|}{ 16. SECURITY CLASSIFICATION OF: } & \multirow{2}{*}{$\begin{array}{l}\text { 17. LIMITATION OF } \\
\text { ABSTRACT } \\
\text { UU }\end{array}$} & \multirow{2}{*}{$\begin{array}{l}\text { 18. NUMBER } \\
\text { OF } \\
\text { PAGES } \\
28\end{array}$} & \multirow{2}{*}{$\begin{array}{l}\text { 19a. NAME OF RESPONSIBLE PERSON } \\
\text { STI Help Desk (email:help@sti.nasa.gov) } \\
\text { 19b. TELEPHONE NUMBER (include area code) } \\
\text { 443-757-5802 }\end{array}$} \\
\hline $\begin{array}{l}\text { a. REPORT } \\
U\end{array}$ & $\begin{array}{l}\text { b. ABSTRACT } \\
\mathrm{U}\end{array}$ & $\begin{array}{l}\text { c. THIS } \\
\text { PAGE } \\
\text { U }\end{array}$ & & & \\
\hline
\end{tabular}



